\title{
Measurement Report: Spatial and vertical variability of aerosol optical properties during MOABAI mobile on-road campaign in North China Plain
}

Ioana E. Popovici ${ }^{1,2}$, Zhaoze Deng ${ }^{3}$, Philippe Goloub ${ }^{1}$, Xiangao Xia ${ }^{3}$, Hongbin Chen $^{3}$, Luc Blarel ${ }^{1}$, 5 Thierry Podvin ${ }^{1}$, Yitian $\mathrm{Hao}^{3, \mathrm{a}}$, Hongyan $\mathrm{Chen}^{3}$, Disong $\mathrm{Fu}^{3}$, Nan Yin ${ }^{3}$, Benjamin Torres ${ }^{1}$, Stéphane Victori $^{2}$, Xuehua Fan ${ }^{3}$

${ }^{1}$ Univ. Lille, CNRS, UMR8518 - LOA - Laboratoire d'Optique Atmosphérique, 59000 Lille, France

${ }^{2}$ R\&D Department, Cimel Electronique, Paris, 75011, France

${ }^{3}$ LAGEO, Institute of Atmospheric Physics, Chinese Academy of Sciences, Beijing, 100029, China

10 a now at: Meteorological Centre of Southwest Air Traffic Management Bureau, CAAC (Civil Aviation Administration of China), Chengdu, 610200, China

Correspondence to: Ioana E. Popovici (i-popovici@cimel.fr)

15 Abstract. The North China Plain (NCP) has been experiencing serious air quality problems since the rapid urbanization and industrialization and has been the subject of many studies over the years. This work presents mapping at a fine scale of the aerosol spatial and vertical variability obtained during the MOABAI campaign (Mobile Observation of Atmosphere By vehicle-borne Aerosol measurement Instruments) using a van equipped with a micro-pulse LIDAR, a sun photometer and in situ instruments, performing on-road measurements. The campaign was conducted from 5 May to 23 May 2017 and had as a main objective to map the pollutants distribution in Beijing and NCP area. A summary of aerosol properties during all measurement days and a comprehensive case study along the industrial Binhai New Area near Tianjin are presented. The highest AOD at $440 \mathrm{~nm}$ (1.34 and 1.9) were recorded during two heavy pollution episodes on 18 May and 19 May 2017, respectively. The lowest PBL (Planetary Boundary Layer) heights $(<1500 \mathrm{~m})$ were recorded during the heavy pollution events, correlated with the highest AOD. Transport of dust from Gobi Desert was captured during the mobile measurements, 
25 impacting Beijing in the 9-13 May period. Exploring the NCP outside Beijing provided datasets in regions with lack of aerosol observation sites and allowed mapping higher aerosol concentrations when passing by polluted cities in NCP (Baoding, Tianjin and Tangshan). In this study, we provide the first mass concentration profiles derived from a mobile micro-pulse LIDAR, making use of complementary information on aerosol type from sun photometer and in situ data. The case study of 17 May 2017 revealed mean extinction coefficients of $0.14 \pm 0.10 \mathrm{~km}^{-1}$ at 532 nm and total mass concentration

30 of $80 \pm 62 \mu \mathrm{g} \mathrm{m}^{-3}$ in the PBL $(<2000 \mathrm{~m})$ for the mobile transect from Tianjin to Tangshan along the coast of Bohai Sea. The highest extinction $\left(0.56 \mathrm{~km}^{-1}\right)$ and mass concentrations $\left(404 \mu \mathrm{g} \mathrm{m}^{-3}\right)$ were found in the industrial Binhai New Area. The PM 10 and $\mathrm{PM}_{2.5}$ fractions of the total mass concentration profiles were separated using the columnar size distribution derived from sun photometer measurements. A general good agreement was found between the lidar-derived PM concentrations at surface level and the ones recorded at the closest air quality stations along the transect, with the only exception along the industrial

35 region near Tianjin port, where emissions were highly variable.

\section{Introduction}

The North China Plain (NCP) in north-eastern China is one of the most populated and polluted regions of China, where longstanding heavy aerosol pollution episodes frequently occur (Chen and Wang, 2015; Yang et al., 2018). The region has undergone rapid development of urbanization and industrialization for rapid economic growth leading to a deterioration in

40 air quality (Han et al., 2015) and becoming one of the regions with the most severe air pollution in China. Some of the most polluted cities in China (Beijing, Baoding, Tianjin, Tangshan, Shijiazhuang) are here and air pollution has become an important concern in this region (An et al., 2019; Sun et al., 2017; Zhu et al., 2016). The major contributor to air pollution is particulate matter (PM), mainly fine particulate matter $\left(\mathrm{PM}_{2.5}\right)$ emitted from fossil fuel, biomass burning, and urban construction (Lei et al., 2011). The NCP is also impacted by frequent dust storms in spring (Yu et al., 2017), studies showing 
45 an increase in dust presence in northeast and northwest regions (Li, 2020). Regional transport plays an important role in urban air pollution. Both local and regional sources contribute to the air pollution in the NCP region, depending on the synoptic conditions, desert dust being advected over NCP when air flows are dominated by westerly winds (Sun et al., 2001) while fine particles pollution events occur with southern winds flow (Chen and Wang, 2015). The measures taken through air pollution control policies show an improvement of air quality and a negative trend for $\mathrm{PM}_{2.5}$ concentrations since 2013

50 (Ma et al., 2018; Zhai et al., 2019). Nonetheless, the pollution levels are still high in NCP, especially during haze episodes, and exceed the air quality limits locally. The ambient air quality standards of the World Health Organization (WHO) for $24 \mathrm{~h}$ average are $25 \mu \mathrm{g} \mathrm{m}^{-3}$ for $\mathrm{PM}_{2.5}$ and $50 \mu \mathrm{g} \mathrm{m}^{-3}$ for $\mathrm{PM}_{10}$, lower than those established by the Ministry of Ecology and Environment of the People's Republic of China (MEE), of 35-75 $\mu \mathrm{g} \mathrm{m}^{-3}$ for $\mathrm{PM}_{2.5}$ and $50-150 \mu \mathrm{g} \mathrm{m}^{-3}$ for $\mathrm{PM}_{10}$. The diversity of emissions and the mixture of pollutants result in complex physical, chemical and optical properties of aerosols in the NCP

55 region, making it an interesting area to study. A number of investigations of air pollution in the NCP achieved using observation sites, aircrafts measurements, mobile laboratories, satellite data and air quality models have been conducted over the years. A review of these studies in NCP is given in Zhu et al. (2016). The observation sites in NCP are generally located in or around large cities, mostly around Beijing, and cannot capture the spatial variability of pollutants at a fine scale. In order to address the air pollution problems in the NCP, it is necessary to identify the distribution of air pollutants in the

60 region and their transport. Observations from a limited number of measurement sites cannot describe this spatial variability and the transport of pollutants in the NCP. For this, a mobile instrumented laboratory performing on-road measurements is useful for identifying the sources of pollution and the areas exceeding the air pollution limits and the regional transport of aerosols.

In this paper, we report on-road remote sensing and in situ measurements of the optical properties, particle size distributions,

65 and spatial and vertical distribution of aerosols in Beijing and NCP area in the 9-19 May 2017 period conducted with a 
mobile instrumented vehicle. The optical properties of aerosols at surface level were measured by in situ. The total column volume size distribution was derived from spectral aerosol optical depth (AOD) measurements. The extinction coefficient profiles derived from LIDAR measurements were converted into total mass concentration profiles with a mass extinction efficiency (MEE) approach. These properties are reported for different pollution levels and for a case study along Tianjin

70 port.

\section{MOABAI campaign}

The MOABAI campaign (Mobile Observation of Atmosphere By vehicle-borne Aerosol measurement Instruments) has been carried out from 5 to 23 May 2017 in North China Plain. The transects of the mobile measurements and the IAP (Institute of Atmospheric Physics) mobile platform are shown in Fig. 1. Remote sensing and in situ instrumentation were involved in the

75 campaign in order to map the spatial and vertical variability of key aerosol properties in Beijing and other polluted cities in the NCP (Baoding, Tianjin, Tangshan). Mobile measurements have been conducted on 10 days, out of which 6 days in Beijing on the $4^{\text {th }}, 5^{\text {th }}$ and $6^{\text {th }}$ ring-roads by day and by night and 4 days outside of Beijing, on the Beijing-Baoding-Tianjin, Tianjin - Tangshan, Tangshan - Beijing and Beijing - Xiahuayuan transects, as shown in Fig.1b.

\subsection{Mobile laboratory}

80 The on-road mobile measurements were conducted with the IAP mobile laboratory shown in Fig.1c, a Mercedes Benz 416 CDI diesel van (length $6.72 \mathrm{~m}$, width $2.01 \mathrm{~m}$, height $2.89 \mathrm{~m}$; payload 5.6 tons). A power generator operated by the engine could continuously supply power when the van was on. An uninterrupted power supply was employed to regulate the voltage and frequency of electricity and could support all instruments for around $8 \mathrm{~h}$ when engine was not working. A cooling system inside the van was used to maintain the temperature constant. The van was equipped with aerosol remote sensing and

85 in situ instruments as well as real-time monitoring trace gas analysers. Table 1 gives an overview of all the instruments on 
board the mobile laboratory, the measured parameters and the temporal resolution and uncertainty for each measurement. Only the measurements of aerosol properties by remote sensing and in situ instruments will be presented in this study. Gasphase parameters measured are not discussed in this study.

The CE370 CIMEL micro-pulse LIDAR (lidar) and the PLASMA (Photomètre Léger Aéroporté pour la Surveillance des

90 Masses d'Air) sun photometer from MAMS (Mobile Aerosol Monitoring System) payload (Popovici et al., 2018) were transported and integrated on site in the existing IAP van already equipped with in situ instruments and gas analysers. The lidar and the sun photometer have been previously used for on-road mobile measurements in France and have been described in details (Popovici et al., 2018). The lidar provided vertical profiles of aerosols and clouds in the troposphere, from $200 \mathrm{~m}$ up to around $12000 \mathrm{~m}$ altitude (molecular detection range, dependent on aerosol concentration) with a vertical resolution of

$9515 \mathrm{~m}$. The data quality was assured by following the Rayleigh fit protocol defined by EARLINET (Freudenthaler et al., 2018). The comparison of the lidar profiles to the molecular profile computed for air density represents the absolute calibration of lidar signals and allows access further to the geophysical parameters such as the backscatter/extinction profiles. The uncertainties of the lidar profiles and the derived parameters have been previously discussed (Popovici et al., 2018) and are shown in Table 1.

PLASMA is the only mobile sun photometer able to track the sun during the vehicle's motion, meets the AERONET standards and is included in the network, referenced as instrument \#650. Compared to CIMEL CE318 sun photometers in AERONET, the current PLASMA model performs only direct sun measurements. The instrument is calibrated by Service National d'Observation, SNO PHOTONS/AERONET-EARLINET, component of ACTRIS (Aerosols, Clouds and Trace gases Research InfraStructure) and French component of AERONET. PLASMA follows the AERONET calibration protocol 
network at Observatoire de Haute Provence (OHP) in France before and after a field campaign. This allows checking the stability of the instrument over time as its characteristics may change.

The in situ instruments consisted of a polar 3- $\lambda$ nephelometer (Aurora 4000 model, Ecotech) (Müller et al., 2011), a 7- $\lambda$ aethalometer (AE33, Maggee Scientific) (Drinovec et al., 2015), a Sky-OPC (11S, GRIMM Aerosol Technik) and trace gas analysers for $\mathrm{NO}_{2}, \mathrm{SO}_{2}$ and $\mathrm{O}_{3}$. Aerosol was sampled using an isokinetic inlet facing forward. The sampled air was split into two flows. One flow was open and directly exposed to in-car air in order to remove the excess air and reduce the pressure in instrument inlets. Tests showed that van speed higher than $20 \mathrm{~km} \mathrm{~h}^{-1}$ could ensure that the open flow was large enough to prevent in-car air to be sampled by instruments downstream. The other flow passed through a nafion drier (MD-700, Perma Pure) and then entered the nephelometer and aethalometer. The Sky-OPC had a separate isokinetic inlet, which could adapt

115 the air velocity within a range of $16-25 \mathrm{~m} \mathrm{~s}^{-1}$ (the speed of van was approximately $60-90 \mathrm{~km} \mathrm{~h}^{-1}$ when assuming the wind speed was 0) using a nozzle with the opening of $1 \mathrm{~mm}$. The gas analysers were calibrated using standard gases before the campaign. The nephelometer was calibrated using air and R134 before the campaign. The flow of the aethalometer was checked before and after the campaign.

Finally, the van was equipped with a weather station that measured the meteorological data (ambient pressure, temperature,

120 relative humidity and wind speed/direction). The driving speed was kept around $90 \mathrm{~km} \mathrm{~h}^{-1}\left(25 \mathrm{~m} \mathrm{~s}^{-1}\right)$, in order to cover as much distance as possible in the NCP region. For the in situ aerosol and gas measurements, the position of the inlets at $3.3 \mathrm{~m}$ above the ground, at the front of the van, was intended to reduce self-pollution from the van's exhaust. The driving speed was also maintained constant when possible, in order to provide a constant sampling flow rate and to reduce contamination from the van's exhaust. The driving speed was higher than the normal wind speed, thereby during the measurements the 125 particles from the exhaust could not reach the inlet in front of the vehicle as a result of the wind from the back of the vehicle. 
The effects of self-pollution can be neglected for the remote sensing instruments as they measure either columnar parameters or vertical profiles starting from $200 \mathrm{~m}$ above ground level.

\subsection{Methods}

A Klett-Fernald-based (Fernald, 1984; Klett, 1981) backward inversion algorithm called BASIC (Mortier, 2013; Mortier et

130 al., 2013a) was used to invert the lidar data in synergy with the sun photometer data. The algorithm requires the lidar range corrected signals (RCS) and the measured AOD to constrain the inversion. The products derived are: extinction coefficient profiles, height-independent lidar ratios (LR) resulted from the iterative process and cloud, aerosol layers and PBL heights. The algorithm's description and applications to real data have been previously shown (Mortier et al., 2013a, 2016; Popovici, 2018; Popovici et al., 2018). The sources of uncertainties have been described (Popovici et al., 2018) and the overall

135 uncertainty for the retrieved aerosol extinction coefficient profiles is considered to be $25 \%$.

In situ measurements were also used in lidar inversion, to improve the extinction profile in the lidar blind zone (0-200 m). The scattering and absorption coefficients measured by the nephelometer and the aethalometer, respectively, were used to compute the extinction coefficients at surface level and a linear interpolation was applied between the lidar-derived extinction value at $200 \mathrm{~m}$ and the extinction measured by in situ at surface level.

140 Nonetheless, care needs to be taken with in situ instruments as they measure the properties of dry particles and not in ambient conditions as it is done by lidar. Some aerosols can uptake water and the effect of relative humidity (RH) is rather constant up to $70 \%$, but a sharp increase of scattering and extinction coefficients is shown for RH $>70 \%$ (Randriamiarisoa et al., 2006; Skupin et al., 2016). The scattering coefficients measured by the nephelometer were corrected for the RH effect following Eq. (1) (Pan et al., 2009):

$145 \sigma_{\text {sca,wet }}=f(R H) \sigma_{\text {sca,dry }}$ 
where $\sigma_{s c a, d r y}$ is the dry scattering coefficient measured by the nephelometer and $f(R H)$ is the aerosol hygroscopic growth factor, defined by the empirical equation Eq. (2) (Pan et al., 2009):

$f(R H)=1+a(R H / 100)^{b}$

where $a$ and $b$ are fitting parameters for specific aerosol types, found in literature. The values used for the case study will be

150 discussed in the dedicated section. For measurements when the $\mathrm{RH}>40 \%$ a correction has been applied, using the RH measured by the weather station on the roof of the mobile platform. The aerosol absorption coefficients were obtained from aethalometer measurements, using correction factors obtained in a comparison study in Beijing between the aethalometer and a 3-wavelength Photoacoustic Soot Spectrometer (PASS-3, Droplet Measurement Technologies).

We used GRASP (Dubovik et al., 2011, 2014, 2019) algorithm and software (https://www.grasp-open.com/, last access: 24

155 March 2020) to retrieve the columnar aerosol volume size distribution (VSD) from spectral AOD measurements performed on-road with PLASMA sun photometer. The GRASP application for only direct sun measurements, called GRASP-AOD, has been previously described (Torres et al., 2017). It relies on statistically optimized fitting of the sun photometer observations and the aerosol is assumed as a mixture of spherical and non-spherical particles, with a defined sphere fraction and an assumed refractive index for the dominant aerosol type. The retrievals provide the six parameters describing the

160 lognormal size distributions for the fine and coarse mode. The uncertainties of the retrieved size distributions lie within 5$10 \%$ for the fine mode and within $10-20 \%$ for the coarse mode (Torres et al., 2017). In this study we show the GRASP-AOD retrievals for a case study of mobile on-road measurements along Tianjin port.

A Mass Extinction Efficiency (MEE) approach (Lagrosas et al., 2005; Lewandowski et al., 2010) has been used to convert the aerosol extinction coefficient profiles derived from the lidar-sun-photometer-in-situ synergy into mass concentration

165 profiles. The MEE relates the total column extinction coefficient to the total mass concentration of aerosols, computed for defined aerosol characteristics, and is defined by Eq. (3) (Lewandowski et al., 2010): 
$M E E=\frac{\pi \int_{r_{\min }}^{r_{\max }} r^{2} Q_{\operatorname{ext}}(r, m, \lambda) n(r) d r}{\frac{4}{3} \pi \rho \int_{r_{\min }}^{r_{\max }} r^{3} n(r) d r} \quad\left[\frac{1 / \mathrm{m}}{\mathrm{g} / \mathrm{m}^{3}}\right]$

where $r$ is the particle size, $r_{\min }$ and $r_{\max }$ are the limits of the particles size distribution, $n(r)$ is the number size distribution, $Q_{e x t}$ is the Mie extinction efficiency computed for $532 \mathrm{~nm}, m$ is the assumed refractive index and $\rho$ is the particle density.

170 The MEE has been computed assuming spherical particles and the following aerosol properties: columnar volume size distribution (VSD) retrieved with GRASP-AOD, assumed refractive index and characteristic particle density for fine and coarse modes. The aerosol mass concentration profiles, $M(z)$, have been derived using Eq. (4):

$M(z)=\frac{\sigma_{e x t}(z)}{\operatorname{MEE}} \quad\left[\frac{\mu \mathrm{g}}{\mathrm{m}^{3}}\right]$

where $\sigma_{\text {ext }}(z)$ is the aerosol extinction coefficient profile and $M E E$ has been previously defined.

175 This methodology has been previously applied for volcanic ash mass concentration estimations (Mortier et al., 2013) and for mass concentrations profiles for mobile observations in France (Popovici et al., 2018). The uncertainty on the mass concentration profiles comes from the uncertainties on the extinction coefficient profiles, the aerosol size distribution, the assumed refractive index and the particles density. The overall uncertainty on the mass concentration profiles is estimated to be between $35 \%$ and $45 \%$. The parameters used for computing the MEE and their uncertainty for the case study are

180 presented in the results section.

\section{Results}

\subsection{Overview of aerosol properties}

An overview of the aerosol optical properties is presented in this section, namely the AOD and Angstrom Exponent (AE) from PLASMA sun photometer and the Range Corrected Signals (RCS) and Planetary Boundary Layer (PBL) height from 


\subsubsection{Spatial distribution of AOD and Angstrom Exponent}

The spatial distribution of AOD at $440 \mathrm{~nm}$ and Angstrom Exponent (AE) between 440 and 870 nm are shown in Fig. 2. The maps show the aerosol optical properties variability at different scales: fine scale $(5 \mathrm{x} 3 \mathrm{~km}$ grid) of the city of Beijing (Fig. $2 \mathrm{a}$ and Fig. 2g), medium scale (50x30 km grid) around the $5^{\text {th }}$ ring road of Beijing (Fig. 2b-c and Fig. 2h-i) and regional scale (200x250 km grid) in the Great Plain of North China (Fig. 2e and Fig. 2k). A different AOD scale was chosen for each figure in order to show the fine spatial variability. The details of each mobile transect, the AOD, AE and PBL height ranges are summarized in Table 2 . Four mobile observations $\left(9,11,13\right.$ and 19 May) were conducted on Beijing's $4^{\text {th }}, 5^{\text {th }}$ and $6^{\text {th }}$ ringroads (Fig. 2a-d, Fig. 2f and Fig. 2g-j, Fig. 2l) and three of the mobile observations were carried out outside Beijing, in the NCP, on 16 May (Beijing- Baoding-Tianjin (AB)), 17 May (Tianjin-Tangshan (BC)) and 18 May (Tangshan-Beijing (CA))

195 (Fig. 2e and Fig. 2k). Five types of days were observed: one day of heavy pollution (0.72 \pm 0.06$)$ in Beijing (9 May) with desert dust contribution (AE of $0.79 \pm 0.05$ ), one dust episode (AE of $0.05 \pm 0.07$ ) in Beijing (11 May) with moderate aerosol loading $(0.37 \pm 0.07)$, one clean day $(0.12 \pm 0.02)$ in Beijing (13 May) but still with dust contribution (AE of $0.67 \pm$ 0.04), two moderate pollution days (0.32-0.45) outside Beijing (16 and 17 May) consisting mainly of fine particles (AE of 1.12-1.23), but also with desert dust contribution in altitude and two heavy pollution (0.86-1.69) days (18 and 19 May), with predominance of fine particles (AE of 1.31-1.41). Low AE values were recorded when north-westerly winds prevailed, Beijing and NCP being downwind of Asian dust storms, on the transport path from Gobi desert, while the highest AOD and AE were recorded during regional heavy pollution episodes when air masses moved from the south. For the moderate pollution and clean situations there was a contribution of both fine and coarse particles, indicated by AE values between those for dust and fine particles episodes. For indication, the average AOD and AE in Beijing during spring are 0.8 and 1 ,

205 respectively (Yu et al., 2017). Lower AE in spring compared to other seasons show the impact of dust episodes, as observed also during our mobile measurements in MOABAI campaign. 


\subsubsection{Vertical variability and PBL height}

Figure 3 shows the vertical distribution of aerosol layers and clouds as seen by the mobile lidar during the on-road measurements in NCP. Most days were clear sky, except for 16 and 19 May afternoon, when cirrus clouds were present, explaining the lack of AOD measurements. The AOD at $440 \mathrm{~nm}$ and the PBL height are also depicted in Fig. 3 to show the correlation between the low PBL height and the high AOD values.

HYSPLIT (Hybrid Single Particle Lagrangian Integrated Trajectory, Stein et al., 2015) backward trajectories for 72 h were performed for all days. For 9 May, which was a pollution day with dust intrusion, the air masses originated from $\mathrm{S}$ direction for the layers up to $2000 \mathrm{~m}$ above ground level, while the aerosol layers at 3000-4000 m altitude were transported from NW

215 direction, suggesting desert dust component (also suggested by lower AE values). The back trajectories for the dust episode (11 May) showed air masses from NW direction (Inner Mongolia), transporting dust from Gobi desert. For the clean day (13 May) air masses originated from $\mathrm{N}$, bringing clean air over Beijing, with a small contribution of residual dust up to $4000 \mathrm{~m}$ altitude. The dust event in the 11-14 May 2017 period has been discussed in Li et al. (2018). Higher particle concentrations near the surface (increase in lidar backscatter signal) and lower PBL height compared to previous days were observed when passing by polluted cities (Baoding, Tianjin, Tangshan) and industrial regions (Tianjin coastal area). The lowest PBL height (500-1700 m) were recorded on the days with moderate and heavy fine particles pollution (16, 17, 18 and 19 May), when air masses flowed from S and SW directions, passing over polluted cities in the NCP (Baoding, Shijiazhuang, Tianjin). The lofted aerosol layers observed at around $2000 \mathrm{~m}$ above ground level on 16 May and around $3000 \mathrm{~m}$ altitude on 17 May originate from N and NW directions, suggesting dust contribution. For the heavy pollution days (18 and 19 May) there is a

225 clear correlation between the high AOD (0.86-1.69) and the low PBL height (500-1600 m). It has been previously reported that heavy pollution episodes occur when the air masses move from S direction (Yu et al., 2017). Our mobile measurements showed also that heavy pollution episodes impact the whole NCP region. 


\subsection{Case study: Tianjin coastal area, 17 May 2017}

\subsubsection{Study area and meteorological conditions}

230 The mobile transect and the local time of measurements are presented in Fig. 4a. We started the mobile measurements at 08:30 local time (UTC+08:00) from the city of Tianjin, heading south and then continuing along the Bohai sea coast, passing through the industrialized Binhai New Area in the 12:00 - 13:30 time interval and then heading northeast to Tangshan and stopping at Guye around 16:00 local time. The weather was fair, with clear sky along the whole transect, ambient temperatures $(\mathrm{T})$ in the $24^{\circ}-30^{\circ} \mathrm{C}$ range and relative humidity $(\mathrm{RH})$ in the $30-65 \%$ range, with a noticeable increase of $\mathrm{RH}$

235 along the coast (Fig. 5c). Backward trajectories (Fig. 8b) at $0 \mathrm{~m}$ and $500 \mathrm{~m}$ altitude show a S-SE flux and a NW direction for the air masses at $3000 \mathrm{~m}$. It has been reported that southerly winds are associated with heavy pollution (Chen and Wang, 2015; He et al., 2009; Yu et al., 2017), while advection of desert dust to an elevation of $<3000 \mathrm{~m}$ is common when air flows are dominated by westerly winds (Sun et al., 2001).

The Binhai New Area, about $60 \mathrm{~km}$ east of Tianjin city, is an important economic coastal area with large industrial activities,

240 including Tianjin port, the largest port in Northern China and one of the largest ports in the world. The industry sectors vary from machinery factories, petro-chemical manufacturing plants, automotive fitting factories and electronics facilities to sea salt production, shipbuilding and port activity and logistics. The area accounted 271 industrial enterprises in 2012 , resulting in heavy pollution in the region (Kong et al., 2010; Su et al., 2017). Both natural and anthropogenic sources such as wind and soil erosion, sea salt, fossil-fuel combustion, vehicles emissions, construction activities, industrial processes and

245 photochemical reactions contribute to the Particulate Matter (PM), resulting in a complex chemical composition of particles in this region (Ni et al., 2013). It is an interesting study area where the microphysical and optical properties of aerosols are not well characterized, much less at a fine scale. The situation is even more complex in spring as mineral dust transports occur frequently, adding to the anthropogenic pollution. One previous study showing mobile lidar measurements has been 
conducted in Tianjin, in different seasons of 2016 (Lyu et al., 2018). Another study by Su et al. (2017) presents the

variability of aerosol microphysical and optical properties as measured by sun photometers set up at three sites, urban, industrial and coastal areas of Tianjin. Nevertheless, this is the first time on-road mobile lidar, sun photometer and in situ measurements are conducted in Tianjin coastal area.

\subsubsection{Particle size distribution at surface level}

Mean volume size distributions measured by Sky-OPC on 30 minutes road segments are presented in Fig. 4b. In the fine

255 mode, three peaks are observed, centered at $0.28,0.45$ and $0.65 \mu \mathrm{m}$ diameter. In the supermicron range, a broad coarse mode is observed between 1 and $5 \mu \mathrm{m}$, with a distinct peak at $3.5 \mu \mathrm{m}$, seen all along the mobile transect, and a coarse mode centered at $7.5 \mu \mathrm{m}$. Super-coarse particles $(>10 \mu \mathrm{m})$ with mode diameters centered at 13, 18 and $30 \mu \mathrm{m}$ are most probably re-suspended dust. The highest concentrations are observed at $0.28 \mu \mathrm{m}$, showing that fine particles pollution is predominating at surface level. The sampled aerosol were a mixture of regional scale background aerosol and direct emission

260 of vehicles and industry. Both soot and secondary aerosol could contribute significantly in the submicron ambient aerosol. Hildemann et al. (1991) showed that the mass size distributions of both gasoline and diesel cars emissions present a single mode with a peak at $0.2 \mu \mathrm{m}$. Studies on ship emissions show that particles with $D_{p}<0.3 \mu \mathrm{m}$ dominate (Merico et al., 2016; Petzold et al., 2008), which could also explain the increase of the fine mode centered at $0.28 \mu \mathrm{m}$ when passing by the Tianjin port in our case. The peak at $0.65 \mu \mathrm{m}$ could correspond to particulate sulphate and ammonium, as shown by Zhuang et al. 265 (1999) in a study conducted on a coastal site in Hong Kong. According to the same study, the nitrates dominated at a coarse mode diameter of $3.95 \mu \mathrm{m}$, which could explain the peak at $3.5 \mu \mathrm{m}$ in our case. The explanation for the high increase in particle concentrations in the Binhai New Area is two-fold. On one hand, we passed by a region with significant higher pollution (industry emissions, intense traffic emissions), so higher particles concentrations. On the other hand, the increase in concentration could be an effect of particle growth in the presence of higher RH. A clear correlation between the increase of 

hygroscopic in humid marine environment (Popovicheva et al., 2009). In our case, if particles smaller than $0.25 \mu \mathrm{m}$ (the minimum detectable diameter of Sky-OPC) would increase in size due to water uptake, they would be counted in the upper size bins, resulting in an increase of particles number in the upper size bins. An increase in concentration is observed for particles in the $0.25<D_{p}<0.8 \mu \mathrm{m}$ range, meaning that, according to our hypotheses, these particles could be more hygroscopic and affected by water uptake. Another interesting event depicted in Fig. 5 is a clear episode of sea breeze, between 12:10 and 13:40, marked by sudden increase of RH correlated with drop in temperature. This sea breeze event suggests that sea salt was transported inland. Sea salt have diameters higher than $0.3 \mu \mathrm{m}$ and are highly hygroscopic (Randles et al., 2004). According to the review of Heintzenberg et al. (2000), the size distribution of marine aerosols presents 3 distinct modes in the fine mode, centered at $0.05,0.15$ and $0.4 \mu \mathrm{m}$ diameter, which could explain the increase of particles 280 at 0.45 but this does not suffice to discriminate a marine aerosol contribution.

\subsubsection{Aerosol scattering and absorption at surface level}

The scattering (at $525 \mathrm{~nm}$ ), absorption (at $520 \mathrm{~nm}$ ) and extinction coefficients derived from nephelometer and aethalometer measurements at surface level, as well as the T and RH monitored by the mobile weather station are presented in Fig. 5. The aethalometer data was averaged on $30 \mathrm{~s}$ and the RH correction to scattering coefficients (Eq. (1) in Sect. 2.2) was applied to

285 the nephelometer data in order to compute the ambient (wet) extinction coefficients at surface level. The $a$ and $b$ parameters in Eq. (2) used for the RH correction are as follows: i) $a=2.3$ and $b=6.27$ for the polluted aerosol type according to Pan et al. (2009) on the pollution segments of the mobile transect (08:40-12:00 and 13:30-16:00 local time) and ii) $a=3.26$ and $b=3.27$, following Liu et al. (2008) for mixed urban-marine aerosols for the transects with sea salt intrusion (12:00-13:30 local time). The mean absorption, scattering (wet) and extinction at surface level were $0.05 \pm 0.03 \mathrm{~km}^{-1}, 0.24 \pm 0.11 \mathrm{~km}^{-1}$ and $2900.29 \pm 0.12 \mathrm{~km}^{-1}$ respectively, where the standard deviations represent the spatio-temporal variability along the route. An 
increase of both scattering and absorption coefficients is observed in the 12:00-13:30 time interval, when scattering rises as high as $0.83 \mathrm{~km}^{-1}$ and absorption up to $0.22 \mathrm{~km}^{-1}$. The mean SSA (Single Scattering Albedo) for the whole transect was 0.84 \pm 0.07 .

Figure 6 shows the comparison between the in situ extinction coefficients at surface level and the lidar-derived extinction at from in situ data are depicted in order to show the impact of the $f(R H)$ correction on the segments where the RH $>50 \%$. The lidar-derived extinction coefficients at $210 \mathrm{~m}$ altitude agree very well with the in situ extinction at surface level. This good agreement between lidar and in situ gives confidence in the overlap correction used for the lidar data and shows that the assumption of homogeneity from the surface up to $\sim 200 \mathrm{~m}$ altitude (constant extrapolation) is reasonable for most of the mobile measurements. Significant differences are observed in the 12:00-13:30 time interval, probably due to the inhomogeneity of the aerosol distribution from ground to $200 \mathrm{~m}$ altitude. The extinction in this time interval measured by in situ and corrected for RH effects, is on average 2 times higher than the lidar-derived extinction. The differences could be explained by the strong increase in particle concentration and/or change in aerosol type only at the surface level and not be « seen » at $200 \mathrm{~m}$ altitude by the lidar. Secondly, the aerosol mixture assumption and the $f(R H)$ correction applied to the nephelometer data could be not appropriate, resulting in an overestimation of scattering coefficients. The lidar-derived extinction coefficients at surface level are highly correlated with the extinction measured by in situ with $R^{2}$ of 0.98 , slope of 0.91 and RMSE of 0.03 all along the transect excluding the values in the 12:00 - 13:30 time interval. The correlation decreases when including the values in this time interval ( $R^{2}$ of 0.9 , slope of 0.53 , RMSE of 0.08 ).

\subsubsection{Columnar volume size distribution}

310 The total column aerosols volume size distributions (VSD) retrieved with GRASP-AOD from PLASMA sun photometer measurements are presented in Fig. 7c-d. Spectral AOD (Fig. 7b) and AE (Fig. 7a) from PLASMA measurements averaged 
on 30 minutes transects, as in Fig. 4a, are also presented. The inversion requires the assumption of the refractive index and of the sphere fraction. Assumptions on the aerosols chemical composition were made based on the modes identified in the insitu-derived size distributions at surface level. An important contribution of elemental carbon (EC), organic carbon (OC) and

315 sulphates was considered, indicated by the narrow fine mode peak at $0.28 \mu \mathrm{m}$, followed by a nitrates component, suggested by the coarse mode centered at $3.5 \mu \mathrm{m}$, a small contribution of dust in altitude (from lidar data and backward trajectories analysis) and sea salt contribution during the sea breeze event. According to a study conducted in Tianjin, in spring 2009 (Han et al., 2012), an average refractive index of 1.52-0.018i was found for a similar aerosol mixture as in our case. For the retrievals, the assumption of spherical particles and a complex refractive index of 1.52-0.008i were used for most of the transect. A lower absorption (imaginary part) was considered taking into account that desert dust was present in the free troposphere. For the part along the coast (12:00-13:30) a complex refractive index of 1.46-0.008i was used, considering the RH effect on aerosols and the sea breeze event, following the results from Schuster et al. (2009) for the aerosol types in our case (fine particles that are predominantly sulphates) and for the maximum relative humidity $(60-65 \%)$. The columnar size distributions present two modes, fine and coarse, centered at $0.3 \mu \mathrm{m}$ and $3.4 \mu \mathrm{m}$ diameter, respectively. The size distributions do not change significantly over the mobile transect, except for an increase in both fine and coarse modes concentrations when reaching the polluted coastal region. The increase in fine mode can be explained by higher particle number concentrations as discussed in Sect. 3.2.2 and the increase in coarse mode along the coast could be explained by the sea salt intrusion during the sea breeze and increase of the nitrates component. The change in particle size is shown by both AE (Fig. 7a) and VSD (Fig. 7c). The highest AE values and slightly higher fine mode were observed in Tianjin, followed by a decrease in AE and an increase of coarse mode in the VSD between 10:00 and 11:30. In the coastal industrial region, the concentrations of both fine and coarse modes increase significantly and AE increases but is still lower than at Tianjin due to an important contribution of coarse mode. The columnar aerosol fine mode concentrations increase by two times in the 
12:00-13:30 time interval, consistent with what is seen at the surface level. Both in situ and columnar VSD present the same positions of the fine and coarse modes diameter at 0.3 and $3.5 \mu \mathrm{m}$, respectively, which shows that the two major aerosol contributions in the fine mode were sulphates and black carbon (BC) and nitrates in the coarse mode.

\subsubsection{Extinction coefficient profiles}

The spatial variability of the extinction coefficients profiles at $532 \mathrm{~nm}$ derived from the synergy of lidar and sun photometer measurements is represented in Fig. 8a. The lidar Klett inversion constrained by AOD was used to get the extinction profiles and the in situ constraint between surface and $200 \mathrm{~m}$ altitude. The mean extinction coefficient in the PBL, from the surface

340 to about $2000 \mathrm{~m}$, was $0.14 \pm 0.10 \mathrm{~km}^{-1}$ along the whole transect from Tianjin to Tangshan and extinction reaching a maximum of $0.56 \mathrm{~km}^{-1}$ when passing by the industrial coastal region. Table 3 presents the summary of the derived variables, the mean extinction coefficients, lidar ratios and mass concentrations up to $2000 \mathrm{~m}$ altitude for each transect in Fig. $4 \mathrm{a}$. The standard deviations depict the spatio-temporal variability for each segment. The highest extinction coefficients were found near Tianjin city and along the industrial Binhai New Area along the coast of Bohai Sea. Some examples of extinction

345 coefficient and mass concentration profiles along the route are depicted in Fig. 9: at Tianjin (08:55), between Tianjin and Binhai New Area (10:50), when crossing a salt pan (12:30), when crossing Tianjin port (13:00) and near Tangshan (15:20). In the free troposphere, an elevated aerosol layer at 2200-3500 m was observed all along the mobile transect. The HYSPLIT backward trajectories at $0 \mathrm{~m}, 500 \mathrm{~m}$ and $3000 \mathrm{~m}$, starting at 13:00 local time (05:00 UTC), illustrated in Fig. 8b, show that the layer at about $3000 \mathrm{~m}$ is transported from Inner Mongolia while the aerosols in the PBL have a local origin. The

350 separation of the elevated dust layer (Fig. 10) has been done using the first derivative of the extinction profiles and applying a threshold to separate the aerosol contributions above PBL. The mean extinction coefficient of the dust layer was $0.05 \pm$ $0.03 \mathrm{~km}^{-1}$, with a maximum of $0.15 \mathrm{~km}^{-1}$ at $2900 \mathrm{~m}$ around 10:30. The mean AOD at $532 \mathrm{~nm}$ of the dust layer is $0.06 \pm 0.01$, which represents $18-20 \%$ of the total measured AOD. 
The variability of height-independent extinction-to-backscatter ratio or lidar ratios (LR) at 532 nm derived from lidar-sunthe spatio-temporal variability in each segment. The LR values decrease from $66 \pm 10$ sr at Tianjin to $35 \pm 12$ sr when crossing the Binhai New Area and then increase again to $57 \pm 14$ sr near Tangshan. The decrease in the LR indicates a change in the aerosol type. The LR around $60 \mathrm{sr}$, found at Tianjin and Tangshan, are characteristics for urban-industrial aerosol type (Cattrall et al., 2005; Müller et al., 2007) while the LR around 40 sr correspond to a marine aerosol type (Ackermann, 1998; Müller et al., 2001, 2007). In our case it is most probably a mixture of continental polluted and marine polluted aerosols (considering the sources along the coast), with a contribution of desert dust in altitude. The values found at Tianjin and Tangshan are consistent with a study in Shangdianzi, located in the northern part of the North China Plain, where a mean LR of $60 \mathrm{sr}$ was found (Hänel et al., 2012). The LR found along the coast are similar to the values of $33 \pm 14$ sr found at a site on the French coast (Boyouk et al., 2011) and of 40 sr found on the Portuguese coast (Ansmann et al., 2001).

Both studies evidenced the presence of a sharp peak in the backscatter signal in the marine boundary layer ranging between 200 and $650 \mathrm{~m}$ when the air masses were coming from the sea direction, which is similar to what is observed in our case, a strong increase in the scattering coefficients below $200 \mathrm{~m}$ when reaching the coast. The sea salt presence in the atmosphere in this region is evident as salt pans are located at the places where the peaks were observed. The Tianjin municipality has a long history of sea salt exploitation and there were still two saltpans exploited at that time according to (Wang et al., 2015), illustrating the coastal landscape map of Tianjin Binhai New Area in 2013. The strong increase of extinction coefficients seen below $200 \mathrm{~m}$ and decrease of the columnar LR correspond to the time intervals when the mobile system was crossing the salt pans and could be linked to a strong presence of sea salt. 


\subsubsection{Mass concentration profiles}

The vertical profiles of aerosols total mass concentration derived from lidar measurements using the Mass Extinction information on the aerosol volume size distributions (VSD), particle density ( $\rho$ ) and complex refractive index (CRI). The mean columnar VSD derived from sun photometer measurements showed an almost equal contribution of fine and coarse mode particles all along the mobile transect. For the estimations of the mass concentration, the parameters of the mean VSD were used (Table 4). Using the aerosol properties previously discussed, we defined an urban-industrial aerosol model for the particles inside the PBL, up to $2000 \mathrm{~m}$, and a desert dust model for the dust layer at 2200-3500 m. The parameters for the urban-industrial aerosol model are summarized in Table 4. As shown is Sect. 3.2.5, the dust layer in the free troposphere was found to be around $20 \%$ of the total AOD, so from the total column coarse particles. This contribution was subtracted from the total coarse VSD and the rest of the VSD was considered as characteristic for the aerosols in the PBL ( $<2000 \mathrm{~m})$. A bimodal VSD and a ratio of coarse-to-fine mode particles concentration $(\mathrm{Cc} / \mathrm{Cf})$ of 0.8 was used for the mass calculations for the PBL. The average particle density was calculated based on the chemical composition (sulphate, nitrate, EC, OC, residue) and correspondent particle densities $\left(1.76,1.73,2,1.4,2.3 \mathrm{~g} \mathrm{~cm}^{-3}\right)$ following Han et al. (2012), and using the sea salt density $\left(1.3 \mathrm{~g} \mathrm{~cm}^{-3}\right)$ as in Tsekeri et al. (2017). A value of $1.75 \mathrm{~g} \mathrm{~cm}^{-3}$ was obtained for particles inside the PBL. The CRI used for the mass calculations was 1.52-0.008i. For the dust aerosol model, we used a mono-modal coarse mode VSD, a CRI of $1.5-$ $0.005 \mathrm{i}$ and a particle density of $2.6 \mathrm{~g} \mathrm{~cm}^{-3}$, characteristic for desert dust. The standard deviations of the parameters in Table 4 correspond to the variability of the retrieved VSD presented in Fig. 7d and were propagated to the calculations, to show the impact of different parameters on the mass concentrations estimations (Table 4). An MEE of $1.79 \mathrm{~m}^{2} \mathrm{~g}^{-1}$ was found for the fine-dominant aerosol model in the PBL and an MEE of $0.54 \mathrm{~m}^{2} \mathrm{~g}^{-1}$ for the dust layer. Other studies found MEE values of 0.5-1.09 $\mathrm{m}^{2} \mathrm{~g}^{-1}$ for Saharan dust (Córdoba-Jabonero et al., 2016). For fine particles, a higher MEE (2.87-6.64 $\left.\mathrm{m}^{2} \mathrm{~g}^{-1}\right) \mathrm{was}$ 
found for $\mathrm{PM}_{2.5}$ in cities in China (Cheng et al., 2017), but in our case the size distribution shows an important contribution

of both coarse and fine particles.

Some examples of mass concentration profiles are presented in Fig. 9. The mean mass concentration in the dust layer was 95 $\pm 52 \mu \mathrm{g} \mathrm{m}^{-3}$ with a maximum of $284 \mu \mathrm{g} \mathrm{m}^{-3}$. The mean total mass concentration in the PBL, for different segments along the mobile transect, is presented in Table 4 and is around $80 \pm 62 \mu \mathrm{g} \mathrm{m} \mathrm{m}^{-3}$ for the whole transect. The standard deviations represent the variability along each transect segment. The highest particle mass concentrations were recorded near Tianjin city, until 09:30, and when crossing the industrial coastal region, from 12:00 to 14:00. The $\mathrm{PM}_{10}$ and $\mathrm{PM}_{2.5}$ fractions of the total particle mass concentrations were calculated as the percentage of particles with $\mathrm{D}_{\mathrm{p}}<10 \mu \mathrm{m}$ and $\mathrm{D}_{\mathrm{p}}<2.5 \mu \mathrm{m}$, respectively, from the total volume concentration of the VSD defined for aerosols in the PBL. Using this method, it was found that the $\mathrm{PM}_{10}$ and $\mathrm{PM}_{2.5}$ represented $95 \%$ and $56 \%$, respectively, of the total mass. The lidar-derived $\mathrm{PM}_{10}$ and $\mathrm{PM}_{2.5}$ mass concentrations at surface level and the hourly $\mathrm{PM}_{10}$ and $\mathrm{PM}_{2.5}$ recorded at air quality (AQ) stations along the mobile transect are presented in Fig. 11. The $\mathrm{PM}_{10}$ and $\mathrm{PM}_{2.5}$ measured at the AQ stations closest to the mobile transect were considered. Despite all the limits for a direct comparison with AQ measurements and the uncertainties and assumptions used for the calculations, there is a rather good agreement between the lidar-derived mass and AQ measurements.

The estimation of aerosol mass concentration is a complex issue involving numerous assumptions, namely the particles size distribution, particles shape, chemical composition, mixing state and the homogeneity and stationarity of all these parameters with height. Thus, the associated uncertainties are also difficult to be evaluated. In this study, the standard deviation of each parameter given in Table 4 was used as a measure of the uncertainty. To this adds the uncertainty on the extinction profiles, considered to be $25 \%$. The highest uncertainty is introduced by the assumed particle density, with an impact of $20 \%$, followed by the complex refractive index, with an impact of $13 \%$ on the mass concentration. Considering the errors as statistically independent, an overall uncertainty of $32 \%$ was evaluated for mass concentration profiles. The levels recorded 
415 at AQ are within the uncertainty of the estimated mass concentrations. In order to give an order of magnitude for the difference between the air quality and the lidar-derived mass concentrations, a mean difference was calculated considering the hourly means from AQ stations and the closest value in time from lidar data. A mean difference of $10 \%$ and $42 \%$ was obtained for $\mathrm{PM}_{10}$ and $\mathrm{PM}_{2.5}$, respectively. This comparison is only indicative, since the hourly mean concentrations recorded at air quality stations are not directly comparable with the 1-minute mass concentrations from mobile measurements. Despite all the assumptions and uncertainties involved in the mass concentration calculations, we believe that the advantages of this method for lidar community and for aerosol data modelling outweigh its limitations.

\section{Conclusions}

Numerous studies on air pollution have already been performed in North China Plain region, although, there are none conducting measurements during motion with mobile lidar and mobile sun photometer. The novelty of this study consists in observations with a mobile vehicle equipped with lidar, sun photometer and in situ instruments (nephelometer, aethalometer, particle counter) deployed to capture the aerosols spatial distribution in Beijing and NCP. Constraining the lidar inversion with a lidar ratio (LR) computed using the AOD measured by the sun photometer is closer to reality than inversion with a pre-defined constant LR for all profiles, that might not be relevant for the aerosol spatial variability observed along a mobile transect. Most lidars do not see well close to the surface, and therefore miss important part of the boundary layer.

430 Photometers measure all the atmospheric column, including this layer never seen by lidar or not accurately seen by lidar. In situ data at surface level complement the missing information from lidar. The combination lidar-photometer-in-situ is the only way to profile properly the entire aerosol column, which is presented in this study. In addition, there is a European effort made in the frame of ACTRIS (Aerosol Cloud and Trace Gas infrastructure) research infrastructure, to put these three 
distinct communities (lidar, photometer and in situ) working together since synergies are the solution for future and open the

435 way to many new applications. For example, this method is applicable to fixed sites having in situ, lidar and sun photometer. The applications of such mobile system having lidar and sun photometer are numerous. Mapping AOD with a mobile sun photometer allows the validation of satellite measurements at different scales; no other instrument at ground can do that spatially in so many points. Studies showing profiles of aerosol mass concentration are scarce in the literature. The new scientific results presented in this study are profiles of aerosols mass concentration (not only at surface level) computed

440 using an improved method (lidar, sun photometer and in situ), that allows more accurate calculations, compared to other methods. Different aerosol plumes (smoke, dust, volcanic) and their variability can be tracked spatially to the source and their contribution (AOD, mass concentration) to the vertical profile evaluated. We showed the added value of such mobile system through the MOABAI campaign.

A summary of the various atmospheric situations (clean, pollution, dust) observed during MOABAI campaign and of the

445 AOD, Angstrom Exponent and PBL height was given. A comprehensive analysis focused on a case study in a heavily polluted and complex area, between Tianjin and Tangshan cities and the Tianjin port (Binhai New Area) was presented. Profiles of aerosols mass concentration were derived from lidar-sun-photometer-in-situ synergy. Using the columnar volume size distribution retrieved from AOD sun photometer measurements, we evaluated the $\mathrm{PM}_{10}$ and $\mathrm{PM}_{2.5}$ fractions of the total mass concentrations at ground level, which compare well to the air quality measurements. The results presented show the potential capabilities of lidar measurements for air quality applications, such as mapping spatially the $\mathrm{PM}_{10}$ and $\mathrm{PM}_{2.5}$ concentrations at surface level and vertically using a mobile system. Mass concentration profiles of dust, volcanic ash and smoke plumes and their spatial distribution are key parameters for different authorities. These measurements are valuable for aviation alerts in case of disruptive events (such as volcanic ash intrusions) and tracking aerosols dynamics and regional 
transport, useful for air quality modelling. The results of this work demonstrate that a mobile instrumented vehicle is an

excellent tool for the real-time characterization of aerosol variability and of pollution levels both spatially and vertically.

As perspective to improve the mass concentration profiles, depolarization and spectral lidar measurements will be used to better characterize the aerosol types on the vertical profile. This will be achieved with the dual-wavelength, depolarization micro-lidar CIMEL CE376, which was deployed for mobile on-road measurements of smoke in FIREX-AQ (Fire Influence on Regional to Global Environments and Air Quality) campaign in northwestern US in summer 2019, and for stationary measurements during COBIACC (Campagne d'Observation Intensive des Aérosols et précurseurs à Caillouël-Crépigny) campaign in France (also in summer 2019), focused on monitoring of background and transported aerosols at a rural site. The mobility of sun photometers is advancing also. On one side, the Cimel CE318-T sun-sky-lunar photometer has already been involved successfully in shipborne campaigns (Yin et al., 2019) and was also deployed during FIREX-AQ for mobile car measurements. On the other side, the development of an Advanced PLASMA instrument, performing sun and sky measurements, is in progress. Recently, in France, Marion Dufresne ship in operation in the Indian Ocean has been equipped with such Cimel CE318-T mobile photometer to measure on a permanent basis what AERONET usually measures at a fixed site. In a second step a lidar will be set up also on this mobile exploratory platform. This is opening a new era for mobile automatic lidar and photometer joint observations, really needed to upgrade the MAN (Maritime Aerosol Network, maritime branch of AERONET) still relying on manual measurements. These additional examples show that the number of 470 applications is increasing to which the ACTRIS European effort will contribute with the development of such lidarphotometer retrievals. 
https://doi.org/10.5194/acp-2020-1269

Preprint. Discussion started: 4 May 2021

(c) Author(s) 2021. CC BY 4.0 License.

(c) (i)
Atmospheric

Chemistry

and Physics

Discussions

Data availability. The HYSPLIT dispersion model is available in the NOAA ARL site

475 (https://ready.arl.noaa.gov/HYSPLIT.php). The data may be accessed at http://dx.doi.org/10.17632/tghdvvhtdx.1 (Popovici, Ioana (2021))

Author contributions. The project was conceived and supervised by HC, XX, XF and PG. IP, LB, HC, YH and ZD participated to the field campaign. IP and ZD performed the data analysis. BT helped with GRASP-AOD inversions. IP wrote the manuscript of this paper and all the co-authors contributed with corrections.

Competing interests. The authors declare that they have no conflict of interest.

Acknowledgements. We acknowledge the colleagues at the IAP (Institute of Atmospheric Physics) / CAS (Chinese Academy

of Sciences) for organizing the campaign and for the financial support. We thank the colleagues from Service National d'Observation PHOTONS/AERONET-EARLINET, a component of the ACTRIS infrastructure and Labex CaPPA (Chemical and Physical Properties of the Atmosphere) project for the participation and support. Finally, the authors would like to acknowledge the use of the GRASP inversion algorithm software (http://www.grasp-open.com, last access: 11 December 2020).

Financial support. This research was supported by the strategic priority research program of the Chinese Academy of Science (CAS) (XDA17040511) and is acknowledged by Xuehua Fan. Xiangao Xia acknowledges the support from the National Key R\&D Program of China (2016YFC0200403) and Hongbin Chen gratefully acknowledges the financial support from the National Natural Science Foundation of China (grant no. 41775005 and 41775033). Zhaoze Deng acknowledges the 

was also supported by the CaPPA project (Chemical and Physical Properties of the Atmosphere), funded by the ANR through the PIA (Programme d'Investissement d'Avenir) under contract ANR-11-LABX-0005-01 and by the Regional Council of Hauts-de-France and the European Funds for Regional Economic Development (FEDER) and from the CPER/CLIMIBIO program.

\section{References}

Ackermann, J.: The extinction-to-backscatter ratio of tropospheric aerosol: A numerical study, J. Atmos. Ocean. Technol., 15(4), 1043-1050, doi:10.1175/1520-0426(1998)015<1043:TETBRO>2.0.CO;2, 1998.

An, Z., Huang, R. J., Zhang, R., Tie, X., Li, G., Cao, J., Zhou, W., Shi, Z., Han, Y., Gu, Z. and Ji, Y.: Severe haze in 8657-8666, doi:10.1073/pnas.1900125116, 2019.

Ansmann, A., Wagner, F., Althausen, D., Müller, D., Herber, A. and Wandinger, U.: European pollution outbreaks during ACE 2: Lofted aerosol plumes observed with Raman lidar at the Portuguese coast, J. Geophys. Res. Atmos., 106(D18), 20725-20733, doi:10.1029/2000JD000091, 2001.

Boyouk, N., Léon, J. F., Delbarre, H., Augustin, P. and Fourmentin, M.: Impact of sea breeze on vertical structure of aerosol optical properties in Dunkerque, France, Atmos. Res., 101(4), 902-910, doi:10.1016/j.atmosres.2011.05.016, 2011.

Cattrall, C., Reagan, J., Thome, K. and Dubovik, O.: Variability of aerosol and spectral lidar and backscatter and extinction ratios of key aerosol types derived from selected Aerosol Robotic Network locations, J. Geophys. Res. D Atmos., 110(10), 1-13, doi:10.1029/2004JD005124, 2005. 
515 Chen, H. and Wang, H.: Haze days in North China and the associated atmospheric circulations based on daily visibility data from 1960 to 2012, J. Geophys. Res., 120(12), 5895-5909, doi:10.1002/2015JD023225, 2015.

Cheng, Z., Ma, X., He, Y., Jiang, J., Wang, X., Wang, Y., Sheng, L., Hu, J. and Yan, N.: Mass extinction efficiency and extinction hygroscopicity of ambient PM2.5 in urban China, Environ. Res., 156(February), 239-246, doi:10.1016/j.envres.2017.03.022, 2017.

520 Córdoba-Jabonero, C., Andrey-Andrés, J., Gómez, L., Adame, J. A., Sorribas, M., Navarro-Comas, M., Puentedura, O., Cuevas, E. and Gil-Ojeda, M.: Vertical mass impact and features of Saharan dust intrusions derived from ground-based remote sensing in synergy with airborne in-situ measurements, Atmos. Environ., 142, 420-429, doi:10.1016/j.atmosenv.2016.08.003, 2016.

Drinovec, L., Močnik, G., Zotter, P., Prévôt, A. S. H., Ruckstuhl, C., Coz, E., Rupakheti, M., Sciare, J., Müller, T.,

525 Wiedensohler, A. and Hansen, A. D. A.: The "dual-spot" Aethalometer: An improved measurement of aerosol black carbon with real-time loading compensation, Atmos. Meas. Tech., 8(5), 1965-1979, doi:10.5194/amt-8-1965-2015, 2015.

Dubovik, O., Herman, M., Holdak, A., Lapyonok, T., Tanré, D., Deuzé, J. L., Ducos, F., Sinyuk, A. and Lopatin, A.: Statistically optimized inversion algorithm for enhanced retrieval of aerosol properties from spectral multi-angle polarimetric satellite observations, Atmos. Meas. Tech., 4(5), 975-1018, doi:10.5194/amt-4-975-2011, 2011.

530 Dubovik, O., Lapyonok, T., Litvinov, P., Herman, M., Fuertes, D., Ducos, F., Torres, B., Derimian, Y., Huang, X., Lopatin, A., Chaikovsky, A., Aspetsberger, M. and Federspiel, C.: GRASP: a versatile algorithm for characterizing the atmosphere, SPIE Newsroom, 2-5, doi:10.1117/2.1201408.005558, 2014.

Dubovik, O., Li, Z., Mishchenko, M. I., Tanré, D., Karol, Y., Bojkov, B., Cairns, B., Diner, D. J., Espinosa, W. R., Goloub, P., Gu, X., Hasekamp, O., Hong, J., Hou, W., Knobelspiesse, K. D., Landgraf, J., Li, L., Litvinov, P., Liu, Y., Lopatin, A., 535 Marbach, T., Maring, H., Martins, V., Meijer, Y., Milinevsky, G., Mukai, S., Parol, F., Qiao, Y., Remer, L., Rietjens, J., 
https://doi.org/10.5194/acp-2020-1269

Preprint. Discussion started: 4 May 2021

(c) Author(s) 2021. CC BY 4.0 License.

(c) (i)
Atmospheric

Chemistry

and Physics

Discussions

Sano, I., Stammes, P., Stamnes, S., Sun, X., Tabary, P., Travis, L. D., Waquet, F., Xu, F., Yan, C. and Yin, D.: Polarimetric remote sensing of atmospheric aerosols: Instruments, methodologies, results, and perspectives, J. Quant. Spectrosc. Radiat. Transf., 224, 474-511, doi:10.1016/j.jqsrt.2018.11.024, 2019.

Fernald, F. G.: Analysis of atmospheric lidar observations: some comments., Appl. Opt., 23(5), 652, 540 doi:10.1364/AO.23.000652, 1984.

Freudenthaler, V., Linné, H., Chaikovski, A., Rabus, D. and Groß, S.: EARLINET lidar quality assurance tools, Atmos. Meas. Tech. Discuss., 1-35, doi:10.5194/amt-2017-395, 2018.

Han, L., Zhou, W. and Li, W.: Increasing impact of urban fine particles (PM2.5) on areas surrounding Chinese cities, Sci. Rep., 5, 11-16, doi:10.1038/srep12467, 2015.

545 Han, S., Bian, H., Zhang, Y., Wu, J., Wang, Y., Tie, X., Li, Y., Li, X. and Yao, Q.: Effect of aerosols on visibility and radiation in spring 2009 in Tianjin, China, Aerosol Air Qual. Res., 12(2), 211-217, doi:10.4209/aaqr.2011.05.0073, 2012.

Hänel, A., Baars, H., Althausen, D., Ansmann, A., Engelmann, R. and Sun, J. Y.: One-year aerosol profiling with EUCAARI Raman lidar at Shangdianzi GAW station: Beijing plume and seasonal variations, J. Geophys. Res. Atmos., 117(13), 1-11, doi:10.1029/2012JD017577, 2012.

550 He, X., Li, C., Lau, A. K. H., Deng, Z., Mao, J., Wang, M. and Liu, X.: An intensive study of aerosol optical properties in Beijing urban area, Atmos. Chem. Phys. Discuss., 9(3), 11413-11440, doi:10.5194/acpd-9-11413-2009, 2009.

Heintzenberg1, J., Covert2, D. C. and Van Dingenen3, R.: Size distribution and chemical composition of marine aerosols: a compilation and review, T ellus, 52, 1104-1122, doi:10.1034/j.1600-0889.2000.00136.x, 2000.

Hildemann, L. M., Markowski, G. R., Jones, M. C. and Cass, G. R.: Submicrometer aerosol mass distributions of emissions 555 from boilers, fireplaces, automobiles, diesel trucks, and meat-cooking operations, Aerosol Sci. Technol., 14(1), 138-152, doi:10.1080/02786829108959478, 1991. 
Klett, J. D.: Stable analytical inversion solution for processing lidar returns., Appl. Opt., 20(2), 211-220, doi:10.1364/AO.20.000211, 1981 .

Kong, S., Han, B., Bai, Z., Chen, L., Shi, J. and Xu, Z.: Receptor modeling of PM2.5, PM10 and TSP in different seasons

560 and long-range transport analysis at a coastal site of Tianjin, China, Sci. Total Environ., 408(20), 4681-4694, doi:10.1016/j.scitotenv.2010.06.005, 2010.

Lagrosas, N., Kuze, H., Takeuchi, N., Fukagawa, S., Bagtasa, G., Yoshii, Y., Naito, S. and Yabuki, M.: Correlation study between suspended particulate matter and portable automated lidar data, J. Aerosol Sci., 36(4), 439-454, doi:10.1016/j.jaerosci.2004.10.007, 2005.

565 Lei, Y., Zhang, Q., He, K. B. and Streets, D. G.: Primary anthropogenic aerosol emission trends for China, 1990-2005, Atmos. Chem. Phys., 11(3), 931-954, doi:10.5194/acp-11-931-2011, 2011.

Lewandowski, P. A., Eichinger, W. E., Holder, H., Prueger, J., Wang, J. and Kleinman, L. I.: Vertical distribution of aerosols in the vicinity of Mexico City during MILAGRO-2006 Campaign, Atmos. Chem. Phys., 10(3), 1017-1030, doi:10.5194/acp$10-1017-2010,2010$.

570 Li, J.: Pollution trends in China from 2000 to 2017: A multi-sensor view from space, Remote Sens., 12(2), doi:10.3390/rs12020208, 2020 .

Li, W., Wang, W., Zhou, Y., Ma, Y., Zhang, D. and Sheng, L.: Occurrence and reverse transport of severe dust storms associated with synoptic weather in East Asia, Atmosphere (Basel)., 10(1), doi:10.3390/atmos10010004, 2018.

Liu, X., Cheng, Y., Zhang, Y., Jung, J., Sugimoto, N., Chang, S. Y., Kim, Y. J., Fan, S. and Zeng, L.: Influences of relative 575 humidity and particle chemical composition on aerosol scattering properties during the 2006 PRD campaign, Atmos. Environ., 42(7), 1525-1536, doi:10.1016/j.atmosenv.2007.10.077, 2007.

Lyu, L., Dong, Y., Zhang, T., Liu, C., Liu, W., Xie, Z., Shi, Y. and Shu, X.: Vertical Distribution Characteristics of PM2.5 
Observed by a Mobile Vehicle Lidar in Tianjin, China in 2016, J. Meteorol. Res., 32(February), doi:10.1007/s13351-0187068-z.1.Introduction, 2018.

Ma, Z., Liu, R., Liu, Y. and Bi, J.: Effects of air pollution control policies on PM2.5 pollution improvement in China from 2005 to 2017: a satellite based perspective, Atmos. Chem. Phys. Discuss., 1-23, doi:10.5194/acp-2018-1191, 2018.

Merico, E., Donateo, A., Gambaro, A., Cesari, D., Gregoris, E., Barbaro, E., Dinoi, A., Giovanelli, G., Masieri, S. and Contini, D.: Influence of in-port ships emissions to gaseous atmospheric pollutants and to particulate matter of different sizes in a Mediterranean harbour in Italy, Atmos. Environ., 139(July), 1-10, doi:10.1016/j.atmosenv.2016.05.024, 2016.

585 Mortier, A.: Tendances et variabilites de l'aerosol atmospherique a l'aide du couplage Lidar/Photometre sur les sites de Lille et Dakar, University of Lille., 2013.

Mortier, A., Goloub, P., Podvin, T., Deroo, C., Chaikovsky, A., Ajtai, N., Blarel, L., Tanre, D. and Derimian, Y.: Detection and characterization of volcanic ash plumes over Lille during the Eyjafjallajökull eruption, Atmos. Chem. Phys., 13(7), 3705-3720, doi:10.5194/acp-13-3705-2013, 2013a.

590 Mortier, A., Goloub, P., Podvin, T., Deroo, C., Chaikovsky, A., Ajtai, N., Blarel, L., Tanre, D. and Derimian, Y.: Detection and characterization of volcanic ash plumes over Lille during the Eyjafjallajökull eruption, Atmos. Chem. Phys., 13(7), 3705-3720, doi:10.5194/acp-13-3705-2013, 2013b.

Mortier, A., Goloub, P., Derimian, Y., Tanré, D., Podvin, T., Blarel, L., Deroo, C., Marticorena, B., Diallo, A. and Ndiaye, T.: Climatology of aerosol properties and clear-sky shortwave radiative effects using lidar and sun photometer observations 595 in the Dakar site, J. Geophys. Res., 121(11), 6489-6510, doi:10.1002/2015JD024588, 2016.

Müller, D., Franke, K., Wagner, F., Althausen, D., Ansmann, A. and Heintzenberg, J.: Vertical profiling of optical and physical particle properties over the tropical Indian Ocean with six-wavelength lidar 1. Seasonal cycle, J. Geophys. Res. Atmos., 106(D22), 28567-28575, doi:10.1029/2000JD900784, 2001. 
Müller, D., Ansmann, A., Mattis, I., Tesche, M., Wandinger, U., Althausen, D. and Pisani, G.: Aerosol-type-dependent lidar

Müller, T., Laborde, M., Kassell, G. and Wiedensohler, A.: Design and performance of a three-wavelength LED-based total scatter and backscatter integrating nephelometer, Atmos. Meas. Tech., 4(6), 1291-1303, doi:10.5194/amt-4-1291-2011, 2011.

Ni, T., Li, P., Han, B., Bai, Z., Ding, X., Wang, Q., Huo, J. and Lu, B.: Spatial and temporal variation of chemical doi:10.4209/aaqr.2012.10.0283, 2013.

Pan, X. L., Yan, P., Tang, J., Ma, J. Z., Wang, Z. F., Gbaguidi, A. and Sun, Y. L.: Observational study of influence of aerosol hygroscopic growth on scattering coefficient over rural area near Beijing mega-city, Atmos. Chem. Phys., 9(19), 7519-7530, doi:10.5194/acp-9-7519-2009, 2009.

610 Petzold, A., Hasselbach, J., Lauer, P., Baumann, R., Franke, K., Gurk, C., Schlager, H. and Weingartner, E.: Experimental studies on particle emissions from cruising ship, their characteristic properties, transformation and atmospheric lifetime in the marine boundary layer, Atmos. Chem. Phys., 8(9), 2387-2403, doi:10.5194/acp-8-2387-2008, 2008.

Popovicheva, O., Kireeva, E., Shonija, N., Zubareva, N., Persiantseva, N., Tishkova, V., Demirdjian, B., Moldanová, J. and Mogilnikov, V.: Ship particulate pollutants: Characterization in terms of environmental implication, J. Environ. Monit., 615 11(11), 2077-2086, doi:10.1039/b908180a, 2009.

Popovici, I. E.: Aerosol spatial and temporal variability as seen by Mobile Aerosol Monitoring System (MAMS), http://www.theses.fr [online] Available from: http://www.theses.fr/2018LIL1R070 (Accessed 1 October 2019 ), 2018.

Popovici, I. E., Goloub, P., Podvin, T., Blarel, L., Loisil, R., Unga, F., Mortier, A., Deroo, C., Victori, S., Ducos, F., Torres, B., Delegove, C., Choël, M., Pujol-Söhne, N. and Pietras, C.: Description and applications of a mobile system performing 

2018, 2018.

Randles, C. A., Russell, L. M. and Ramaswamy, V.: Hygroscopic and optical properties of organic sea salt aerosol and consequences for climate forcing, Geophys. Res. Lett., 31(16), 4-7, doi:10.1029/2004GL020628, 2004.

Randriamiarisoa, H., Chazette, P., Couvert, P., Sanak, J. and Mégie, G.: Relative humidity impact on aerosol parameters in a Paris suburban area, Atmos. Chem. Phys., 6(5), 1389-1407, doi:10.5194/acp-6-1389-2006, 2006.

Schuster, G. L., Lin, B. and Dubovik, O.: Remote sensing of aerosol water uptake, Geophys. Res. Lett., 36(3), 1-5, doi:10.1029/2008GL036576, 2009.

Skupin, A., Ansmann, A., Engelmann, R., Seifert, P. and Müller, T.: Four-year long-path monitoring of ambient aerosol extinction at a central European urban site: Dependence on relative humidity, Atmos. Chem. Phys., 16(4), 1863-1876, doi:10.5194/acp-16-1863-2016, 2016.

Stein, A. F., Draxler, R. R., Rolph, G. D., Stunder, J., Cohen, M. D. and Ngan, F.: NOAA'S HYSPLIT ATMOSPHERIC TRANSPORT AND DISPERSION MODELING SYSTEM, Bull. Am. Meteorol. Soc., 96(12), 2059-2077, doi:10.1175/BAMS-D-14-00110.2, 2015.

Su, X., Wang, Q., Li, Z., Calvello, M., Esposito, F., Pavese, G., Lin, M., Cao, J., Zhou, C., Li, D. and Xu, H.: Regional 635 transport of anthropogenic pollution and dust aerosols in spring to Tianjin - A coastal megacity in China, Sci. Total Environ., 584-585(April 2018), 381-392, doi:10.1016/j.scitotenv.2017.01.016, 2017.

Sun, J., Zhang, M. and Liu, T.: Spatial and temporal characteristics of dust storms in China and its surrounding regions, 1960-1999: Relations to source area and climate, J. Geophys. Res. Atmos., 106(D10), 10325-10333, doi:10.1029/2000JD900665, 2001.

640 Sun, L., Li, R. B., Tian, X. P. and Wei, J.: Analysis of the temporal and spatial variation of aerosols in the Beijing-Tianjin- 
Hebei region with a 1 km AOD product, Aerosol Air Qual. Res., 17(3), 923-935, doi:10.4209/aaqr.2016.05.0185, 2017.

Torres, B., Dubovik, O., Fuertes, D., Schuster, G., Eugenia Cachorro, V., Lapyonok, T., Goloub, P., Blarel, L., Barreto, A., Mallet, M., Toledano, C. and Tanré, D.: Advanced characterisation of aerosol size properties from measurements of spectral optical depth using the GRASP algorithm, Atmos. Meas. Tech., 10(10), 3743-3781, doi:10.5194/amt-10-3743-2017, 2017.

645 Tsekeri, A., Lopatin, A., Amiridis, V., Marinou, E., Igloffstein, J., Siomos, N., Solomos, S., Kokkalis, P., Engelmann, R., Baars, H., Gratsea, M., Raptis, P. I., Binietoglou, I., Mihalopoulos, N., Kalivitis, N., Kouvarakis, G., Bartsotas, N., Kallos, G., Basart, S., Schuettemeyer, D., Wandinger, U., Ansmann, A., Chaikovsky, A. P. and Dubovik, O.: GARRLiC and LIRIC: Strengths and limitations for the characterization of dust and marine particles along with their mixtures, Atmos. Meas. Tech., 10(12), 4995-5016, doi:10.5194/amt-10-4995-2017, 2017.

650 Wang, H., Xu, X. and Zhu, G.: Landscape changes and a salt production sustainable approach in the state of salt pan area decreasing on the coast of Tianjin, China, Sustain., 7(8), 10078-10097, doi:10.3390/su70810078, 2015.

Yin, Z., Ansmann, A., Baars, H., Seifert, P., Engelmann, R., Radenz, M., Jimenez, C., Herzog, A., Ohneiser, K., Hanbuch, K., Blarel, L., Goloub, P., Victori, S. and Maupin, F.: Aerosol measurements with a shipborne Sun-sky-lunar photometer and collocated multiwavelength Raman polarization lidar over the Atlantic Ocean, Atmos. Meas. Tech., 12(10), 5685-5698, doi:10.5194/amt-12-5685-2019, 2019.

Yu, X., Lü, R., Liu, C., Yuan, L., Shao, Y., Zhu, B. and Lei, L.: Seasonal variation of columnar aerosol optical properties and radiative forcing over Beijing, China, Atmos. Environ., 166, 340-350, doi:10.1016/j.atmosenv.2017.07.011, 2017.

Zhai, S., Jacob, D. J., Wang, X., Shen, L., Li, K., Zhang, Y., Gui, K., Zhao, T. and Liao, H.: Fine particulate matter (PM2.5) trends in China, 2013-2018: contributions from meteorology, Atmos. Chem. Phys. Discuss., 1-19, doi:10.5194/acp-2019$660279,2019$.

Zhu, Y., Zhang, J., Wang, J., Chen, W., Han, Y., Ye, C., Li, Y., Liu, J., Zeng, L., Wu, Y., Wang, X., Wang, W., Chen, J. and 
https://doi.org/10.5194/acp-2020-1269

Preprint. Discussion started: 4 May 2021

(c) Author(s) 2021. CC BY 4.0 License.

(c) (i)

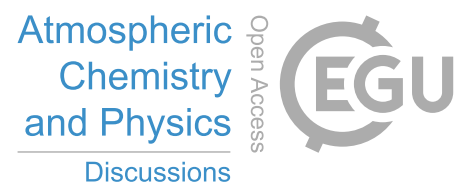

Zhu, T.: Distribution and sources of air pollutants in the North China Plain based on on-road mobile measurements, Atmos.

Chem. Phys., 16(19), 12551-12565, doi:10.5194/acp-16-12551-2016, 2016.

Zhuang, H., Chan, C. K., Fang, M. and Wexler, A. S.: Size distributions of particulate sulfate, nitrate, and ammonium at a

coastal site in Hong Kong, Atmos. Environ., 33(6), 843-853, doi:10.1016/S1352-2310(98)00305-7, 1999.

670 
Table 1 Instrumentation set up in the IAP mobile laboratory for the MOABAI campaign in North China Plain. The aerosol

\section{Aerosol}

\begin{tabular}{|c|c|c|c|c|c|}
\hline Instrument & Make and model & Wavelength (nm) & $\begin{array}{l}\text { Temporal } \\
\text { resolution }\end{array}$ & $\begin{array}{c}\text { physical/chemical/optical } \\
\text { properties }\end{array}$ & Uncertainty \\
\hline Micro pulse & CE370, CIMEL & 532 & $30 \mathrm{sec}$ & Vertical profile & \\
\hline \multirow[t]{3}{*}{ LIDAR } & & & & (Attenuated backscatter) & $15 \%$ \\
\hline & & & & (Extinction coefficient & $25 \%$ \\
\hline & & & & Mass concentration) & $35-45 \%$ \\
\hline
\end{tabular}

\begin{tabular}{|c|c|c|c|c|c|}
\hline \multirow[t]{4}{*}{$\begin{array}{c}\text { PLASMA } \\
\text { sun photometer }\end{array}$} & $\# 650, \mathrm{LOA}$ & $\begin{array}{c}340,380,440,500, \\
675,870,940\end{array}$ & $10 \mathrm{sec}$ & $\begin{array}{c}\text { Column-integrated optical } \\
\text { properties }\end{array}$ & \\
\hline & & 1020,1640 & & (AOD, Angstrom Exponent, & $2 \%(\mathrm{VIS} / \mathrm{NIR})$ \\
\hline & & & & precipitable water) & $3 \%(\mathrm{UV})$ \\
\hline & & & & (Volume Size Distribution) & $10-20 \%$ \\
\hline
\end{tabular}

\begin{tabular}{ccccc}
\hline $\begin{array}{c}\text { Nephelometer } \\
(3-\lambda)\end{array}$ & Aurora 4000, & $450,525,635$ & $30 \mathrm{sec}$ & Scattering coefficient
\end{tabular}

\begin{tabular}{|c|c|c|c|c|c|}
\hline $\begin{array}{c}\text { Aethalometer } \\
(7-\lambda)\end{array}$ & $\begin{array}{c}\text { AE33, } \\
\text { Maggee Scientific }\end{array}$ & $\begin{array}{c}370,470,520,590, \\
660,880,950\end{array}$ & $1 \mathrm{sec}$ & $\begin{array}{c}\text { Absorption coefficient } \\
\text { BC concentration }\end{array}$ & - \\
\hline $\begin{array}{l}\text { Optical Particle } \\
\text { Counter } \\
(0.25-32 \mu \mathrm{m})\end{array}$ & $\begin{array}{c}\text { Sky-OPC model } \\
1.129, \text { GRIMM } \\
\text { Aerosol Technik }\end{array}$ & 655 & $6 \mathrm{sec}$ & $\begin{array}{c}\text { Number concentration } \\
\text { Number size distribution } \\
\mathrm{PM}_{1}, \mathrm{PM}_{2.5}, \mathrm{PM}_{10}\end{array}$ & $5 \%$ \\
\hline $\begin{array}{l}\mathrm{NO}-\mathrm{NO}_{2}-\mathrm{NO}_{\mathrm{x}} \\
\text { analyser }\end{array}$ & $\begin{array}{l}\text { 42i, Thermo } \\
\text { Electron }\end{array}$ & $\mathrm{n} / \mathrm{a}$ & $10 \mathrm{~s}$ & $\mathrm{NO}-\mathrm{NO}_{2}-\mathrm{NO}_{\mathrm{x}}$ concentration & $1 \%$ \\
\hline $\mathrm{SO}_{2}$ analyser & $\begin{array}{l}\text { 43i, Thermo } \\
\text { Electron }\end{array}$ & $\mathrm{n} / \mathrm{a}$ & $10 \mathrm{~s}$ & $\mathrm{SO}_{2}$ concentration & $1 \%$ \\
\hline $\mathrm{O}_{3}$ analyser & $\begin{array}{l}\text { 49i, Thermo } \\
\text { Electron }\end{array}$ & $\mathrm{n} / \mathrm{a}$ & $20 \mathrm{~s}$ & $\mathrm{O}_{3}$ concentration & $1 \%$ \\
\hline Weather station & Airmar & $\mathrm{n} / \mathrm{a}$ & $1 \mathrm{sec}$ & $\begin{array}{l}\text { Pressure, temperature, } \\
\text { relative humidity, wind } \\
\text { speed/direction }\end{array}$ & - \\
\hline
\end{tabular}


Table 2 Summary of mobile transects, dates and aerosol properties observed during the MOABAI mobile measurements: AOD at $440 \mathrm{~nm}$ and Angstrom Exponent (AE) measured by PLASMA sun photometer and PBL height as measured by lidar

\begin{tabular}{ccccc} 
Mobile transect & Date & AOD $(440 \mathbf{~ n m})$ & AE $(\mathbf{4 4 0 - 8 7 0 ~} \mathbf{~ m})$ & PBL height, km \\
\hline Beijing, $4^{\text {th }}$ ring road & 9 May 2017 & $0.62-0.84$ & $0.67-0.87$ & $1.7-2.2$ \\
\hline Beijing, $5^{\text {th }}$ ring road & 11 May 2017 & $0.24-0.55$ & $-0.03-0.27$ & $1.5-3.6$ \\
\hline Beijing, $5^{\text {th }}$ and $6^{\text {th }}$ ring road & 13 May 2017 & $0.08-0.16$ & $0.41-0.83$ & $1.2-3.9$ \\
\hline Beijing-Baoding-Tianjin (AB) & 16 May 2017 & $0.2-0.55$ & $1-1.24$ & $0.3-1.7$ \\
\hline Tianjin-Tangshan (BC) & 17 May 2017 & $0.3-0.79$ & $1-1.9$ & $0.3-1.3$ \\
\hline Tangshan-Beijing (CA) & 18 May 2017 & $0.43-1.34$ & $1.22-1.74$ & $1-1.6$ \\
\hline Beijing, $5^{\text {th }}$ ring-road & 19 May 2017 & $1.47-1.9$ & $1.21-1.51$ & $0.5-1$
\end{tabular}

Table 3. Mean aerosol extinction coefficients and lidar ratios (LR) at $532 \mathbf{~ n m}$ derived from Klett AOD-constraint lidar inversions and mass concentrations in the PBL (0-2000 m), for each time interval correspondent to transect segments depicted in Fig. 4a. The standard deviations correspond to the spatio-temporal variability within each transect segment.

\begin{tabular}{cccc} 
Time interval & $\boldsymbol{\sigma}_{\text {ext }}\left(\mathbf{k m}^{-\mathbf{1}}\right)$ & LR $(\mathbf{s r})$ & Mass concentration $\left(\boldsymbol{\mu} \mathbf{~} \mathbf{~}^{-\mathbf{3}}\right)$ \\
\hline $08: 40-09: 00$ & $0.14 \pm 0.15$ & $66 \pm 10$ & $80 \pm 85$ \\
\hline $09: 00-09: 30$ & $0.15 \pm 0.15$ & $59 \pm 17$ & $85 \pm 82$ \\
\hline $09: 30-10: 00$ & $0.13 \pm 0.10$ & $56 \pm 10$ & $75 \pm 57$ \\
\hline $10: 00-10: 30$ & $0.14 \pm 0.07$ & $52 \pm 12$ & $80 \pm 41$ \\
\hline $10: 30-11: 00$ & $0.13 \pm 0.06$ & $50 \pm 11$ & $74 \pm 34$ \\
\hline $11: 00-11: 30$ & $0.14 \pm 0.06$ & $43 \pm 14$ & $78 \pm 33$ \\
\hline $11: 30-12: 00$ & $0.1 \pm 0.06$ & $46 \pm 14$ & $57 \pm 34$ \\
\hline $12: 00-12: 30$ & $0.18 \pm 0.09$ & $40 \pm 13$ & $100 \pm 50$ \\
\hline $12: 30-13: 00$ & $0.16 \pm 0.13$ & $35 \pm 12$ & $83 \pm 71$ \\
\hline $13: 00-13: 30$ & $0.15 \pm 0.13$ & $39 \pm 11$ & $87 \pm 74$ \\
\hline $13: 30-14: 00$ & $0.15 \pm 0.13$ & $45 \pm 11$ & $73 \pm 60$ \\
\hline $14: 00-14: 30$ & $0.13 \pm 0.11$ & $42 \pm 8$ & $71 \pm 65$ \\
\hline $14: 30-15: 00$ & $0.13 \pm 0.12$ & $52 \pm 12$ & $75 \pm 66$ \\
\hline $15: 00-15: 30$ & $0.13 \pm 0.12$ & $47 \pm 11$ & $71 \pm 59$ \\
\hline $15: 30-16: 00$ & $0.13 \pm 0.11$ & $57 \pm 14$ &
\end{tabular}


https://doi.org/10.5194/acp-2020-1269

Preprint. Discussion started: 4 May 2021

(c) Author(s) 2021. CC BY 4.0 License.

(c) (i)
Atmospheric

Chemistry

and Physics

Discussions

Table 4. Parameters used for the calculations of mass concentration: modal radius for fine, $\mathbf{r}_{\mathrm{mf}}$, and coarse, $\mathbf{r}_{\mathrm{mc}}$, mode, in $\mu \mathrm{m}$, the geometric standard deviation for fine, $\sigma_{f}$, and coarse, $\sigma_{c}$, mode, the ratio of volume concentration of coarse to fine mode, $C_{c} / C_{f}$,

the particle density, $\rho$, in $\mathrm{g} \mathrm{cm}^{-3}$, the real part of the refractive index, $\mathrm{m}_{\mathrm{r}}$ and the imaginary part of the refractive index, $\mathrm{m}_{\mathrm{i}}$.

\begin{tabular}{ccccccccc} 
& $\boldsymbol{r}_{\boldsymbol{m} \boldsymbol{f}}$ & $\boldsymbol{r}_{\boldsymbol{m} \boldsymbol{c}}$ & $\boldsymbol{\sigma}_{\boldsymbol{f}}$ & $\boldsymbol{\sigma}_{\boldsymbol{c}}$ & $\boldsymbol{C}_{\boldsymbol{c}} / \boldsymbol{C}_{\boldsymbol{f}}$ & $\boldsymbol{\rho}$ & $\boldsymbol{m}_{\boldsymbol{r}}$ & $\boldsymbol{m}_{\boldsymbol{i}}$ \\
\hline mean & 0.13 & 1.66 & 0.43 & 0.68 & 0.8 & 1.75 & 1.5 & 0.01 \\
\hline std & 0.01 & 0.03 & 0.01 & 0.03 & 0.1 & 0.34 & 0.05 & 0.005 \\
\hline impact on & $7 \%$ & $0.5 \%$ & $0.7 \%$ & $0.6 \%$ & $4 \%$ & $20 \%$ & $13 \%$ \\
mass (PBL) & & & & & & & & \\
\hline $\begin{array}{c}\text { impact on } \\
\text { mass (dust) }\end{array}$ & - & $2 \%$ & - & $3 \%$ & - & $20 \%$ & $0.1 \%$
\end{tabular}



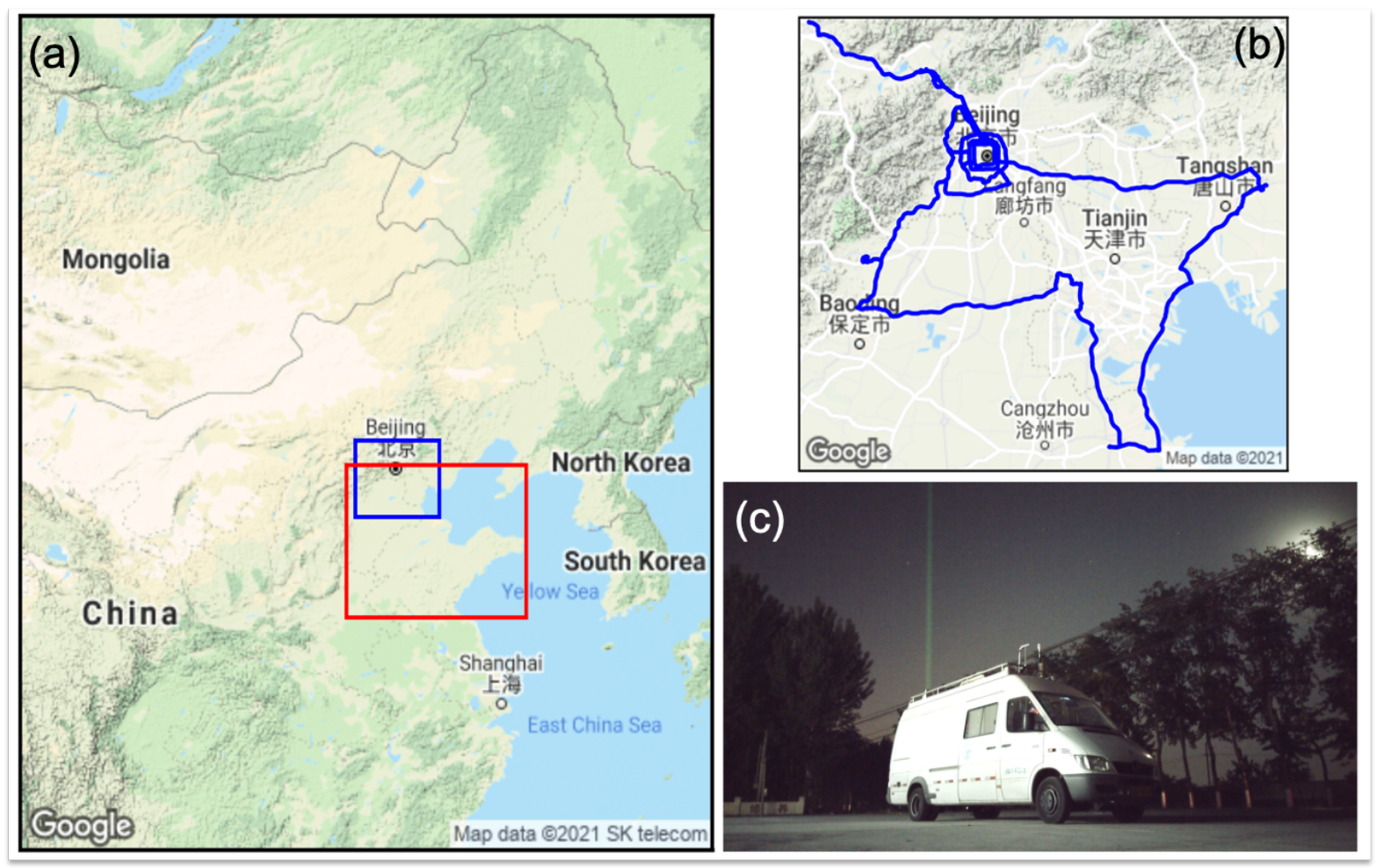

Figure 1: (a) Map of China and neighbour regions showing North China Plain (red rectangle) and area investigated through mobile measurements (blue rectangle), (b) GPS track of all mobile transects and (c) IAP's instrumented van used for the mobile observations; photograph taken at night on 17 May 2017 at Guye $\left(39.71^{\circ} \mathrm{N}, 118.37^{\circ} \mathrm{E}\right)$, near Tangshan. 

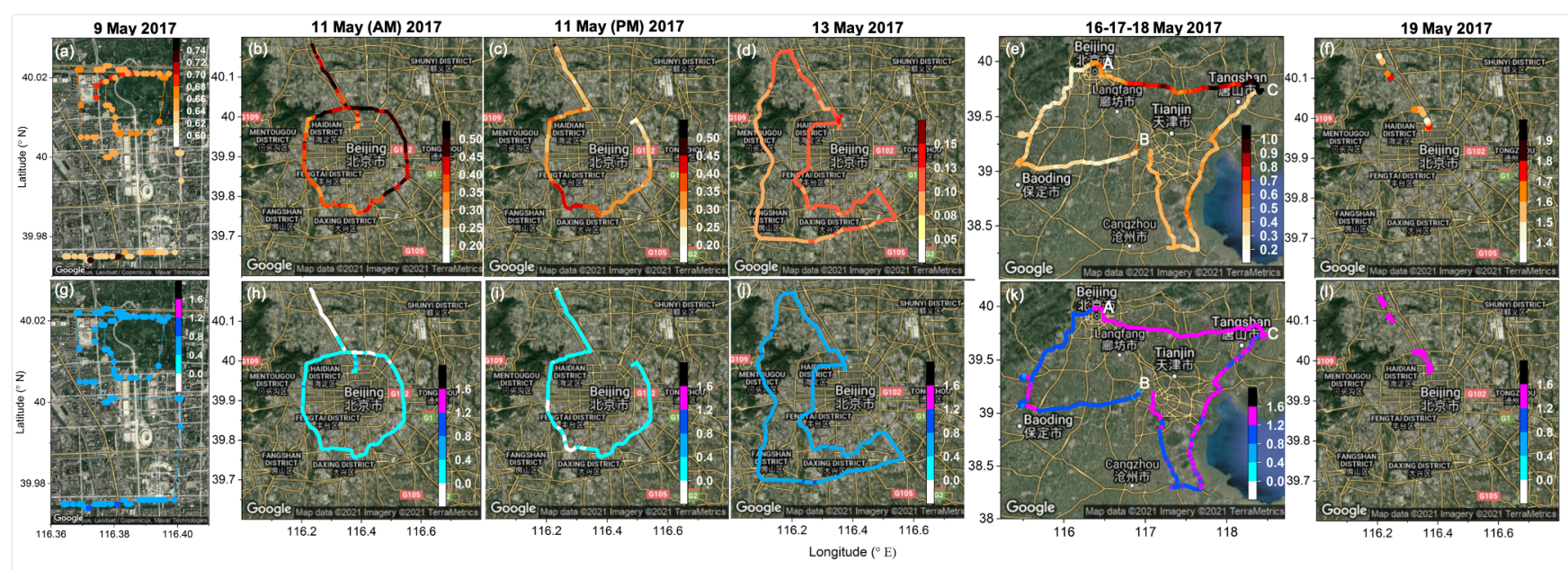

710 Figure 2. Spatial variability of AOD at $440 \mathrm{~nm}$ and (top panels) and Angstrom Exponent (AE) between 440 and $870 \mathrm{~nm}$ (bottom panels), derived from PLASMA sun photometer measurements. The A, B and C (Fig. 2d and 2k) denote the departure and end points for the three transects: Beijing-Tianjin (AB) on 16 May 2017, Tianjin-Tangshan (BC) on 17 May 2017 and TangshanBeijing (CA) on 18 May 2017. Please note that the color scale for the AOD maps is different for each transect in order to show the fine spatial variability.
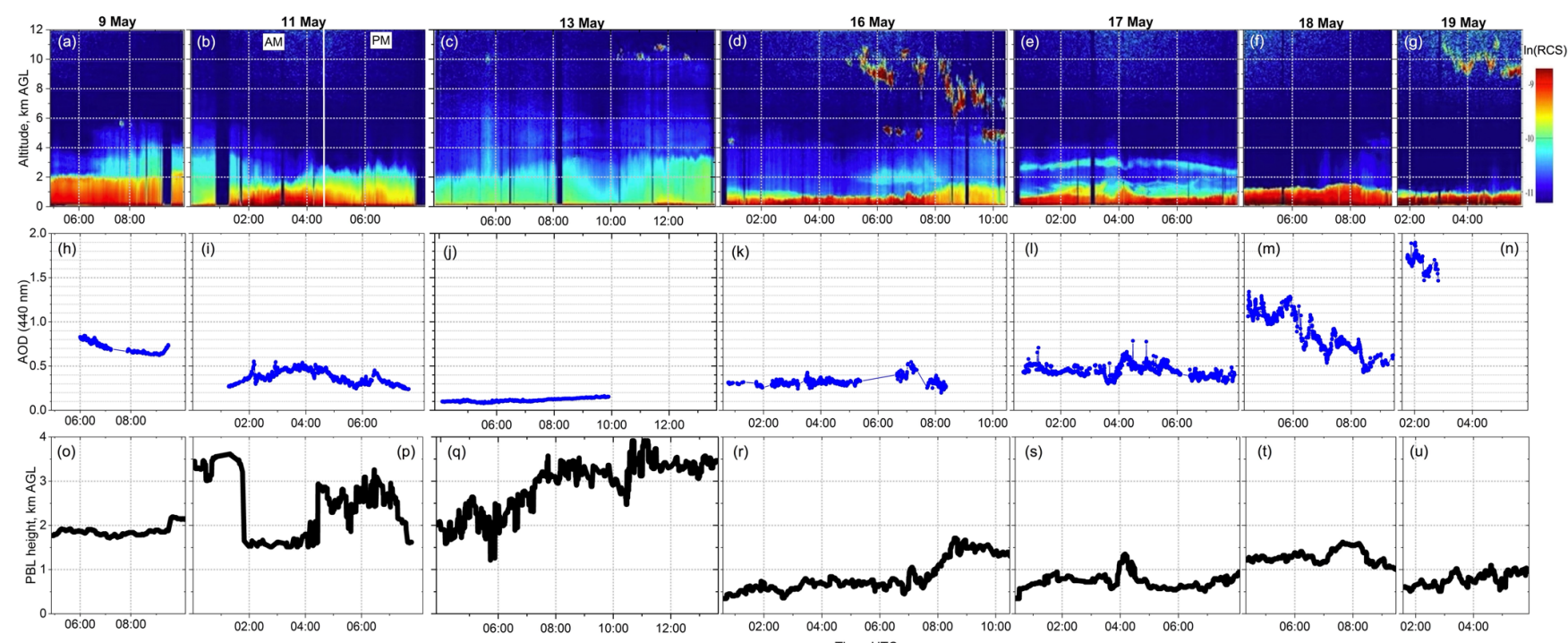

Figure 3. (Top panels) Spatio-temporal and vertical variability of aerosol layers and clouds, colour-coded by lidar Range Corrected Signal (RCS) as measured along the mobile transects detailed in Table 2, (Middle panels) AOD at $440 \mathrm{~nm}$ and (Bottom panels) PBL height. 
https://doi.org/10.5194/acp-2020-1269

Preprint. Discussion started: 4 May 2021

(c) Author(s) 2021. CC BY 4.0 License.

(c) (i)

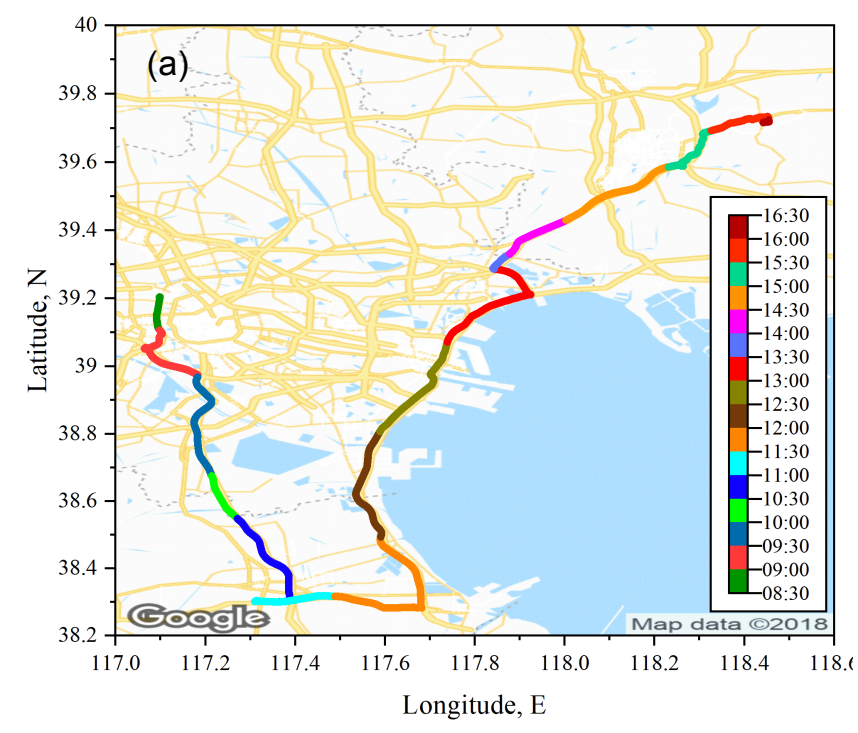

\section{Atmospheric \\ Chemistry \\ and Physics \\ Discussions}

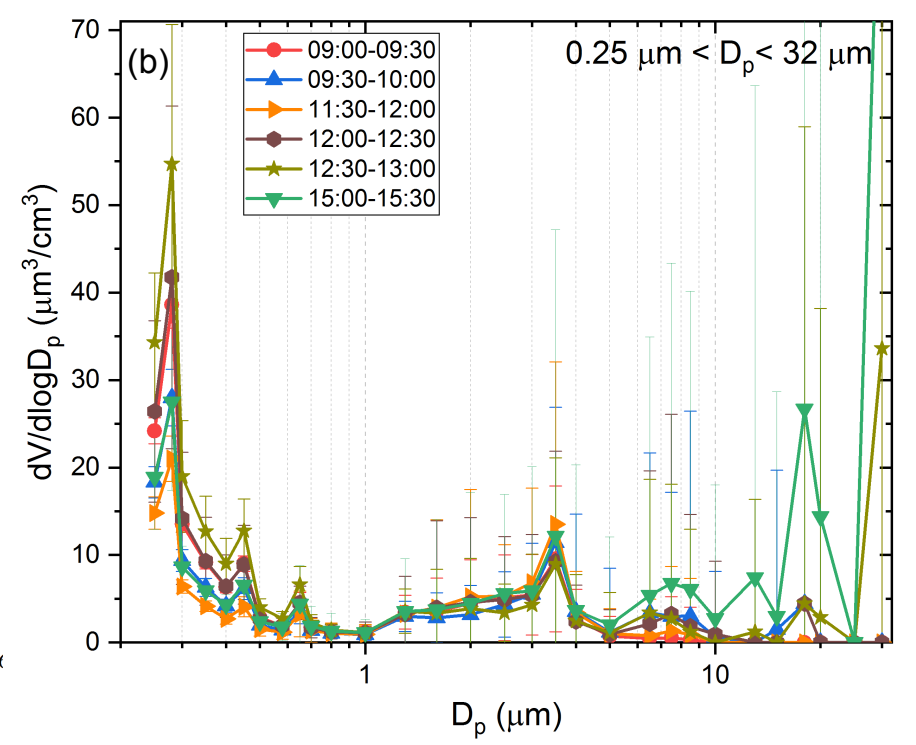

720 Figure 4. (a) GPS track of the mobile transect from Tianjin to Tangshan color coded by 30 minutes time intervals (local time,

$\mathrm{UTC}+8 \mathrm{~h}$ ) and (b) particle volume size distributions measured by Grimm Sky-OPC, averaged on 30 minutes transect segments. 


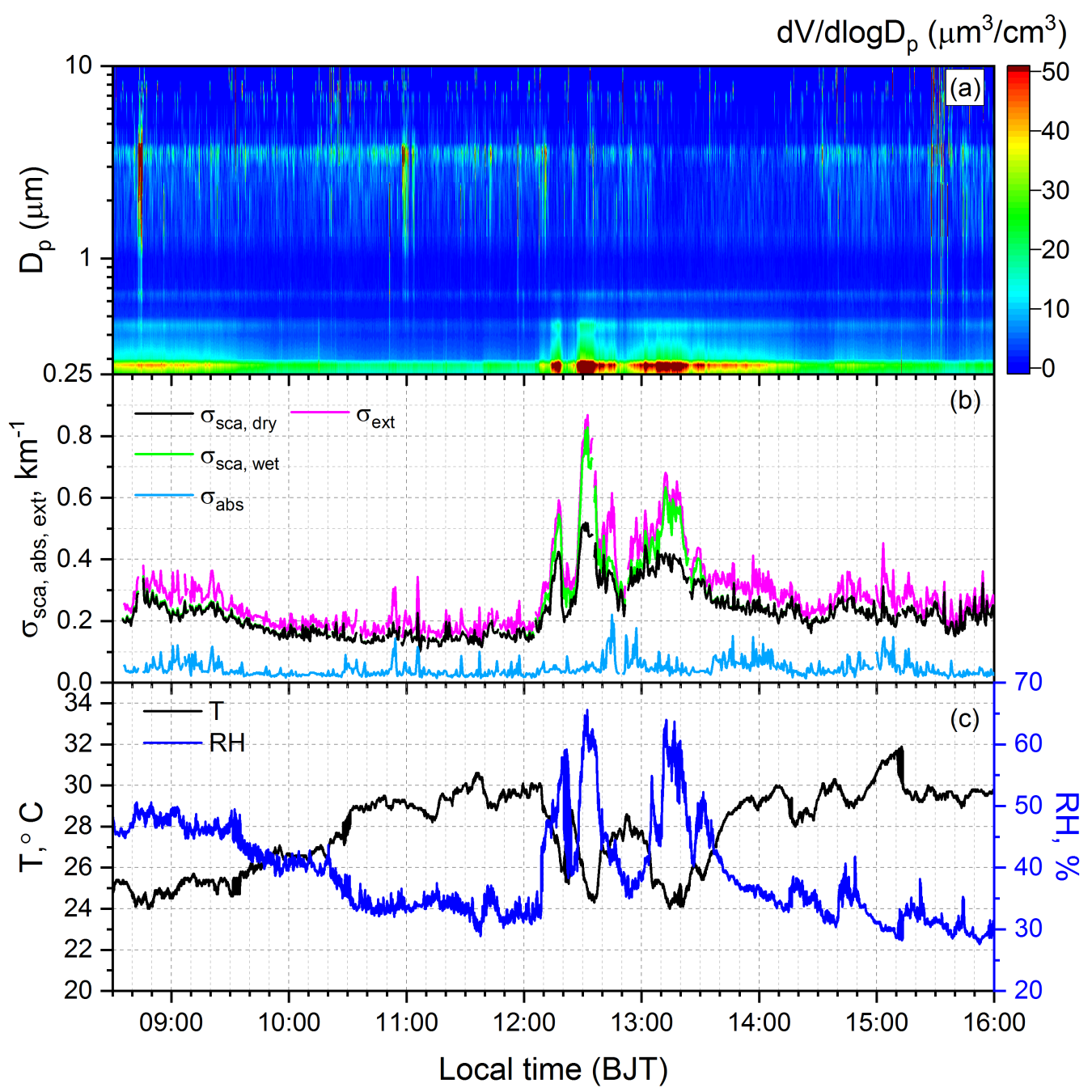

Figure 5. Spatio-temporal variability of (a) particle volume size distribution as measured by Grimm Sky-OPC, (b) scattering coefficient measured by nephelometer (black), scattering coefficient corrected for relative humidity effect (green), absorption coefficient derived from aethalometer measurements (light blue), extinction coefficient computed from nephelometer and aethalometer measurements (magenta) and (c) temperature (T) (black) and relative humidity (RH) (blue) measured by the weather station along the mobile transect from Tianjin to Tangshan on 17 May 2017. 


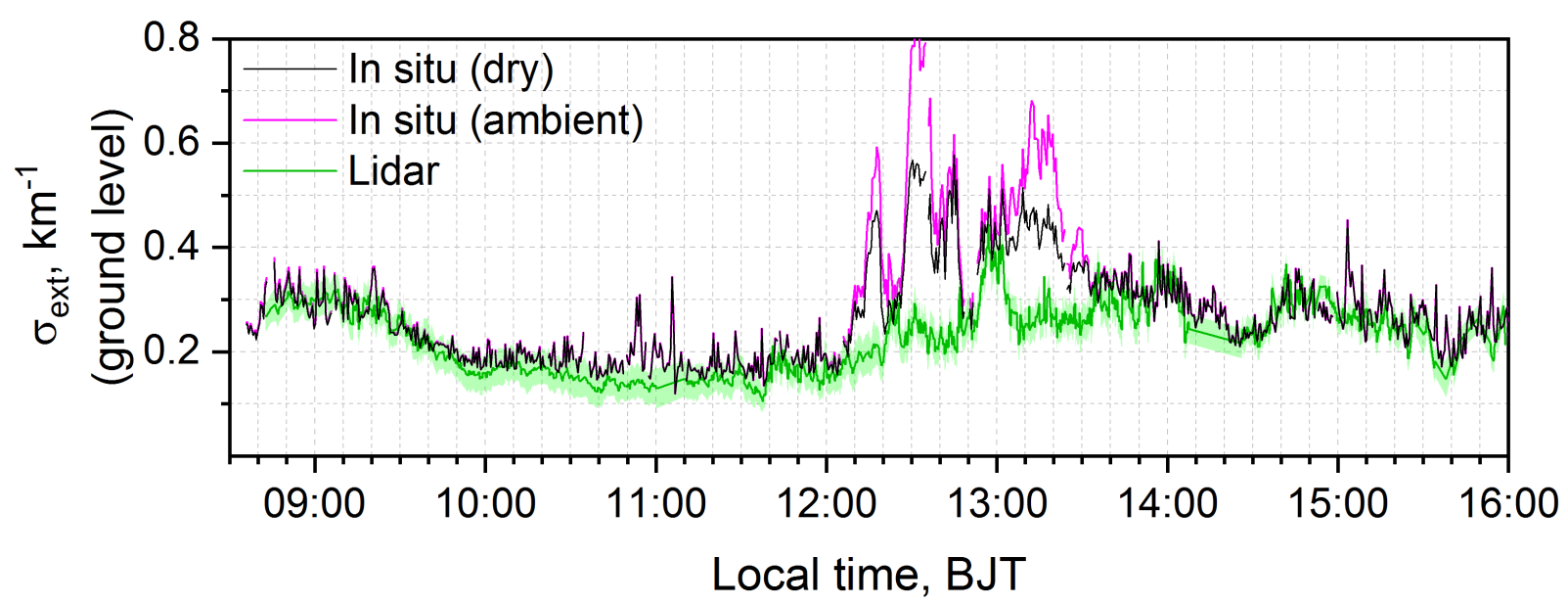

Figure 6. Spatio-temporal variability of aerosol extinction coefficient at $525 \mathrm{~nm}$ derived from in situ measurements (nephelometer and aethalometer) with no correction for RH (black) and with $f(R H)$ correction (magenta) and lidar-derived extinction coefficients at $532 \mathrm{~nm}$ at $210 \mathrm{~m}$ altitude (green). The green shaded area represents the uncertainty on the derived extinction coefficient. 

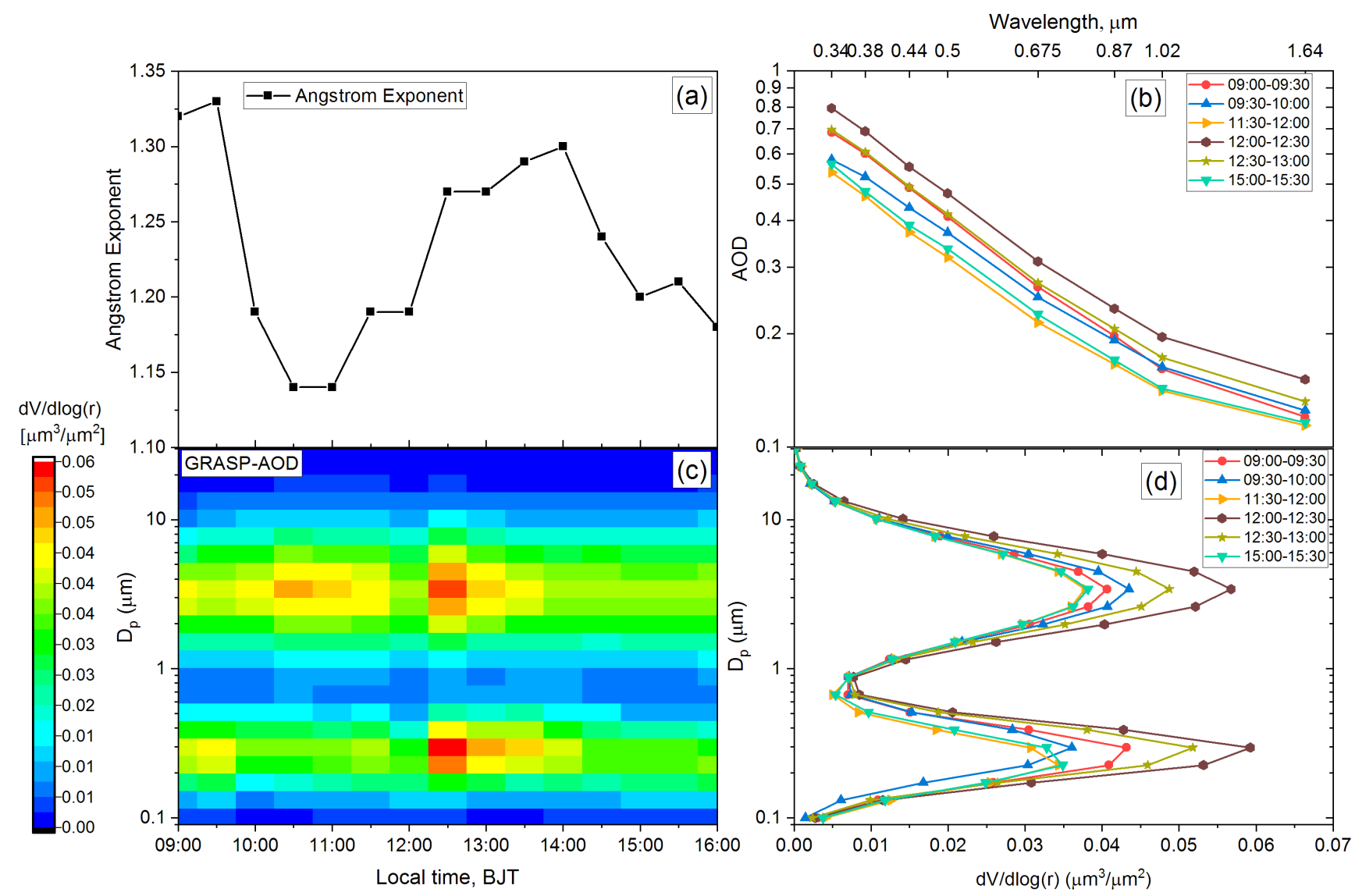

Figure 7. Spatio-temporal variability of (a) Angstrom Exponent (AE), (b) spectral AOD, (c) total column volume size distributions retrieved with GRASP-AOD for every transect segment and (d) columnar volume size distributions for some time intervals along the mobile transect. All size distributions are averaged on 30 minutes time intervals and can be localized on the mobile transect using the map color coded by local time shown in Fig. 4a. 
(a)

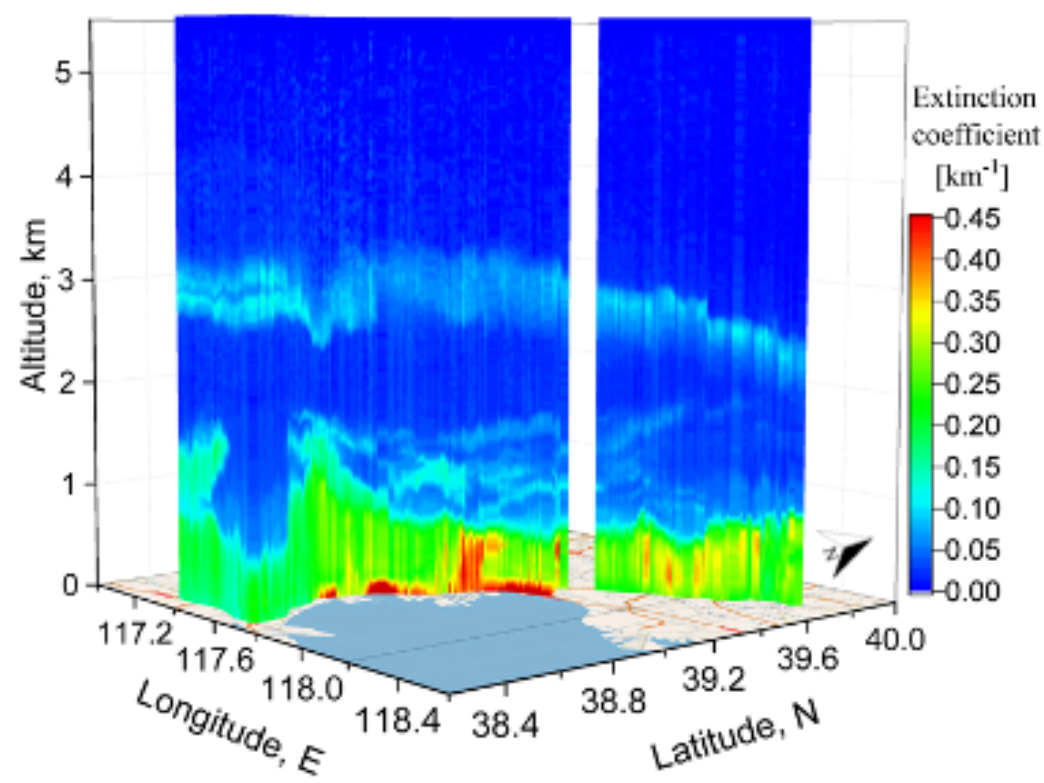

(b) NOAA HYSPLIT MODEL Backward trajectories ending at 0500 UTC 17 May 17 GFSG Meteorological Data

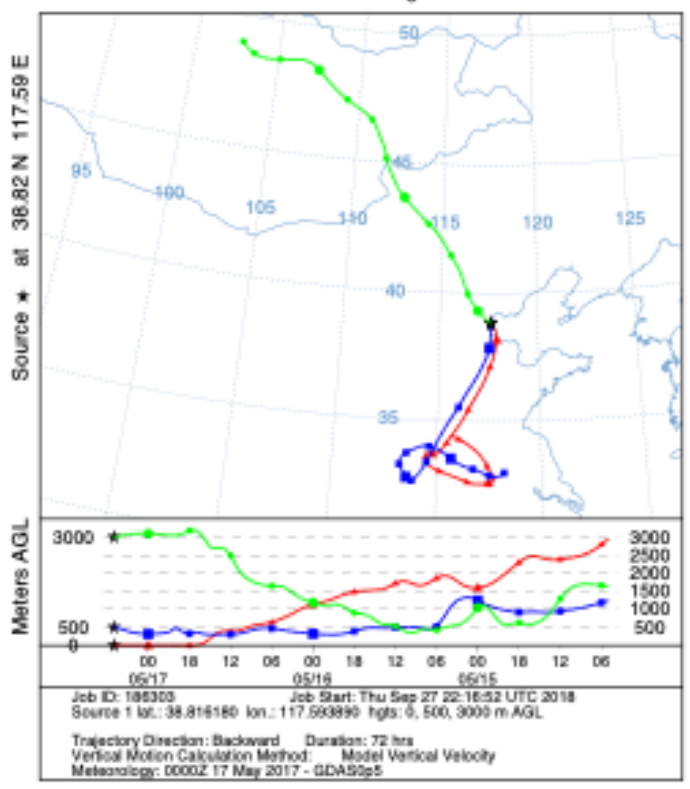

740 Figure 8. (a) 3-D representation of the lidar-derived extinction coefficients profiles at $532 \mathrm{~nm}$ along the mobile transect from Tianjin to Tangshan and (b) $72 \mathrm{~h}$ backward trajectories (Stein et al., 2015 ; HYSPLIT, 2018) arriving at a point along the mobile transect, near Tianjin port $\left(38.82^{\circ} \mathrm{N}, 117.59^{\circ} \mathrm{E}\right)$ on 17 May 2017, 05:00 UTC at heights of $0 \mathrm{~m}$ (red), $500 \mathrm{~m}$ (blue) and $3000 \mathrm{~m}$ (green) above ground level. 


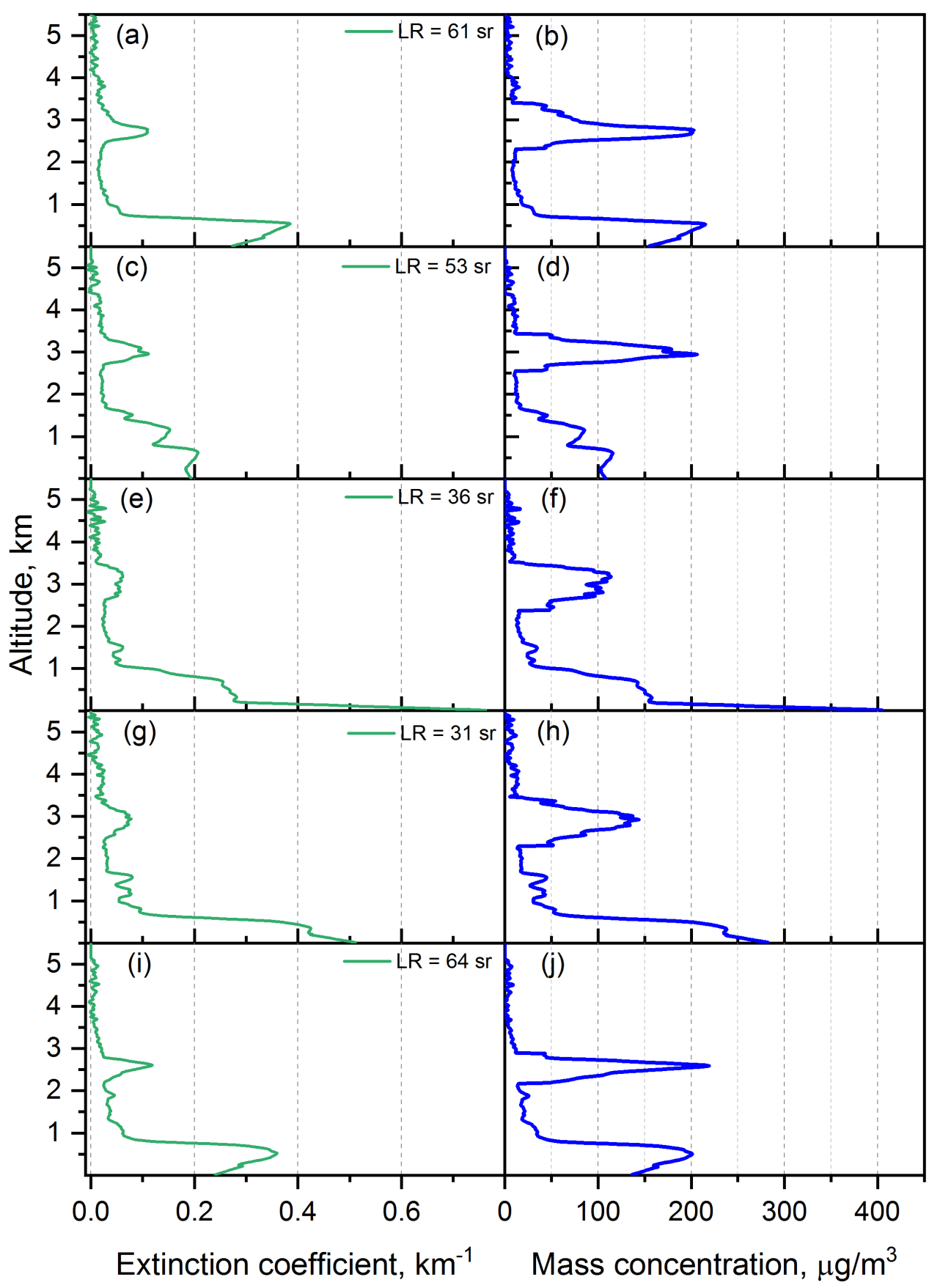

745 Figure 9. (Left) Aerosol extinction coefficient profiles and lidar ratios at $532 \mathbf{~} \mathbf{m}$ and (Right) total mass concentrations profiles for different times along the mobile transect: 08:55 (a, b), 10:50 (c, d), 12:30 (e, f), 13:00 (g, h) and 15:20 (i, j), local time. The extinction profiles were derived using the in situ constraint corrected for RH. 


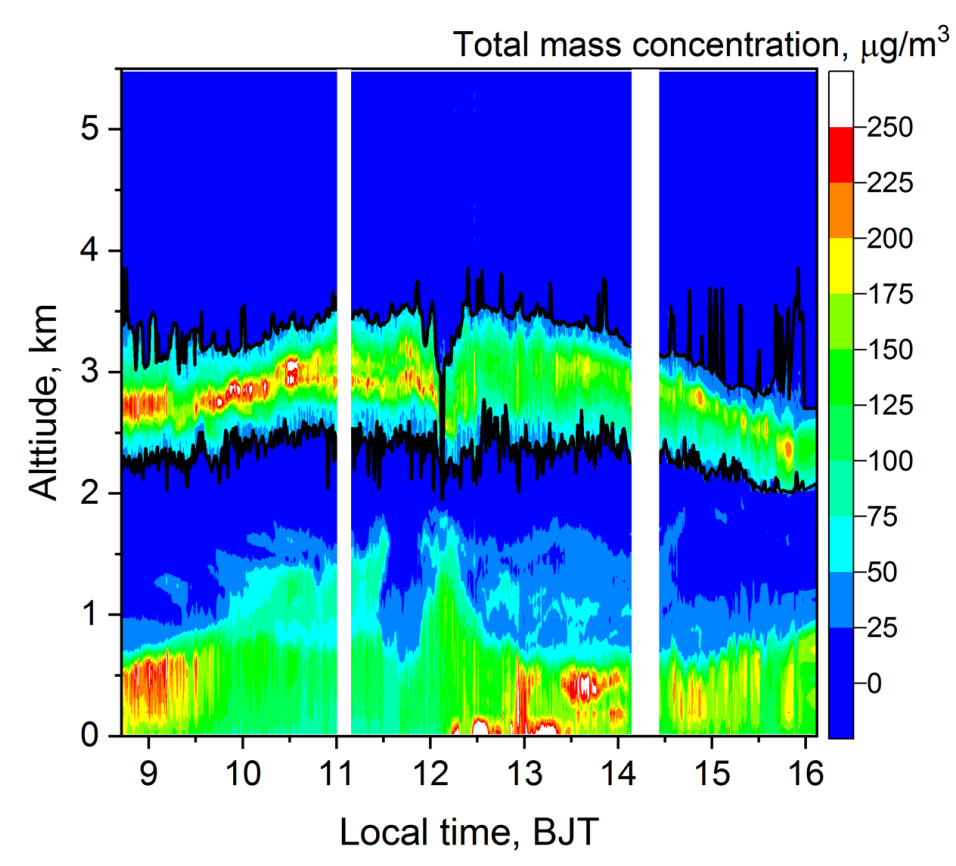

Figure 10. Aerosols total mass concentration profiles derived using the MEE approach on 17 May 2017 along the transect from

750 Tianjin to Tangshan (BJT=Beijing time). The calculations were done considering a dust aerosol model for the layer in the 2000$3500 \mathrm{~m}$ range and an urban-industrial aerosol model for the rest of the profile. 
https://doi.org/10.5194/acp-2020-1269

Preprint. Discussion started: 4 May 2021

(c) Author(s) 2021. CC BY 4.0 License.

(c) (i)
Atmospheric

Chemistry

and Physics

Discussions
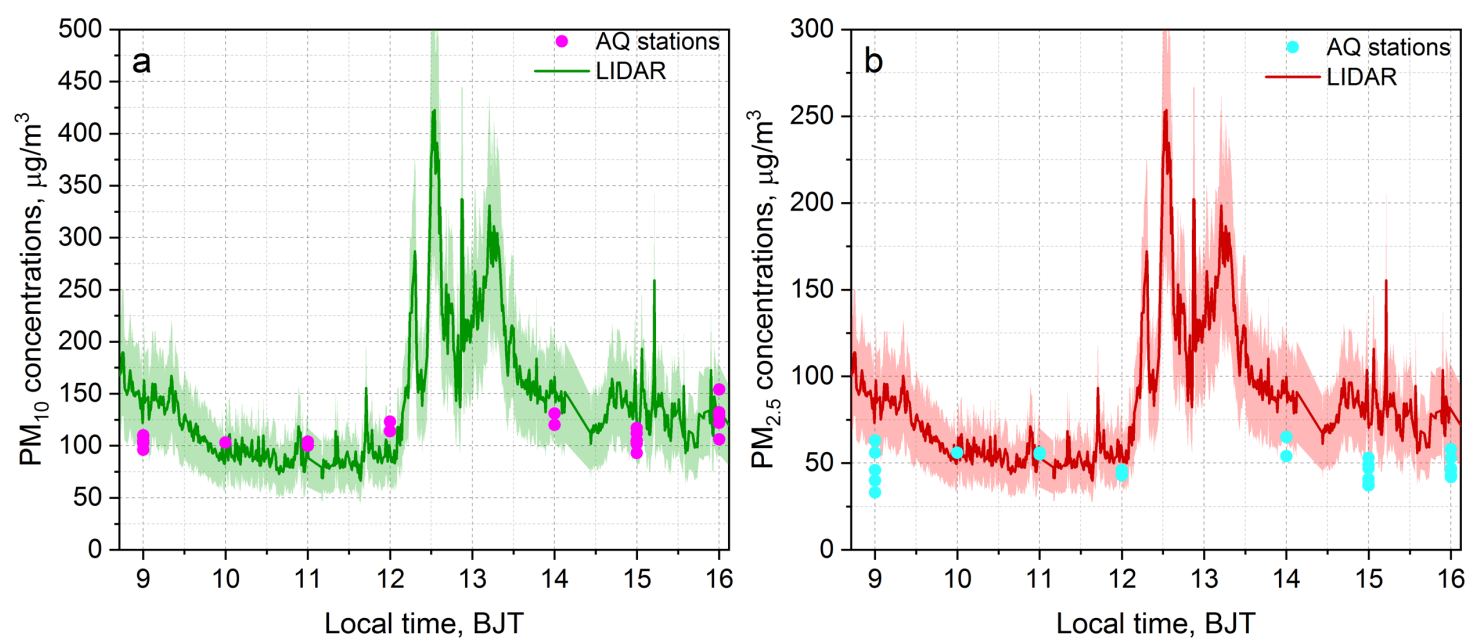

Figure 11. Spatio-temporal variability of (a) $\mathrm{PM}_{10}$ (green) and (b) $P M_{2.5}$ (red) at surface level derived from lidar profiles and the mean hourly $\mathrm{PM}_{10}$ (magenta) and $\mathrm{PM}_{2.5}$ (cyan) measured at the closest air quality (AQ) stations to the route (BJT=Beijing time). The shaded area on each curve represents the uncertainty of $32 \%$ on the lidar-derived mass concentrations. 